\title{
"أثر تقنيات اليزر على جماليات الملابس"
}

أ.د/ عمرو جمال الدين حسونة

أستاذ التصميم بقسم الملابس الجاهزة -

كلية الفنون التطبيقية - جامعة حلوان

م /آيات سمير أحمد أبورجيلة

مديرة مكتب تصميم الملابس Prenda للملابس الجاهزة
أ.د / محمد البدري عبد الكريم أستاذ الآلات بقسم الملابس الجاهزة - كلية

الفنون النطبيقية - جامعة حلوان الفان

أ.م.د / أحمد محمود الشيخ أستاذ مساعد بقسم الملابس الجاهزة - كلية

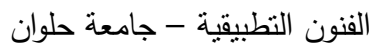

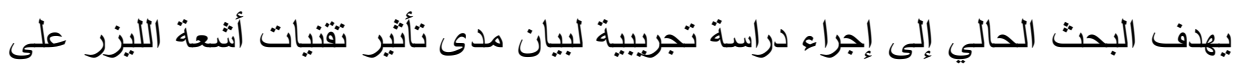

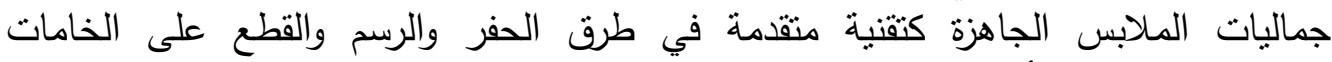
والأقمشة، باعتبارها أدوات وتقنيات هامة في التتكيل والتصميم بهدف ولتهن رفع القيمة الجمالية

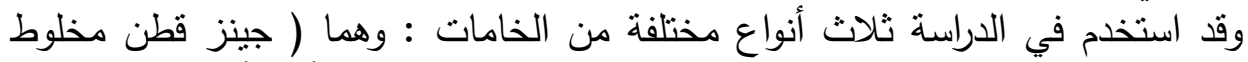

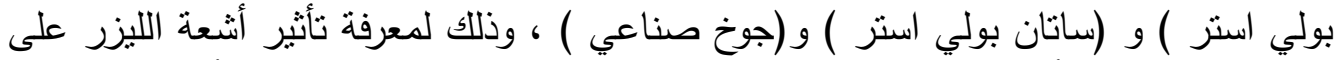

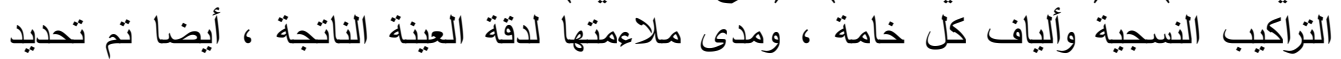

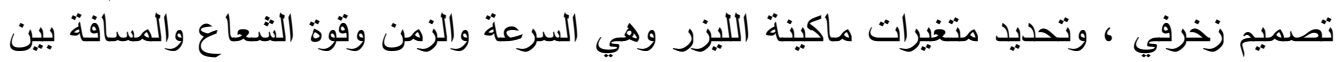

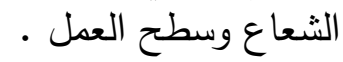
وبعد إجراء عينات الدراسة طبقا للمواصفات والمتغيرات المحددة نم إجراء مجموعة من

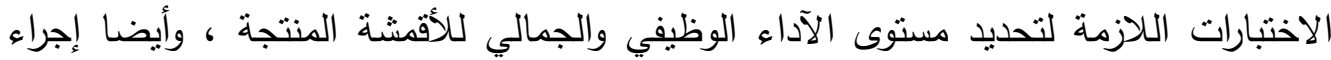

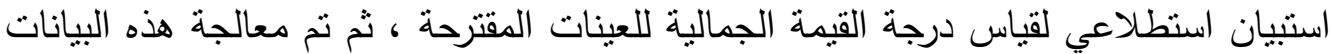

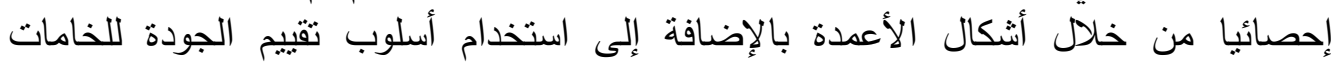

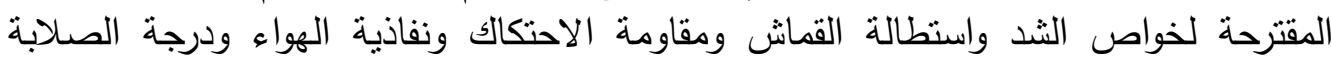

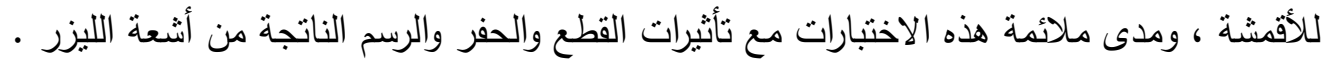

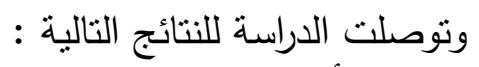
1- أن الخواص الطبيعية والميكانيكية للخامات ترتبط بمعدلات تأثيرات أنتعة الليزر

$$
\text { بصورة كبيرة التواصن }
$$

ץ- أثرت تكنولوجيا الليزر تأثثرا كبيرا على جماليات التصميم ، واستحدثت

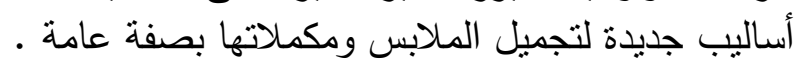

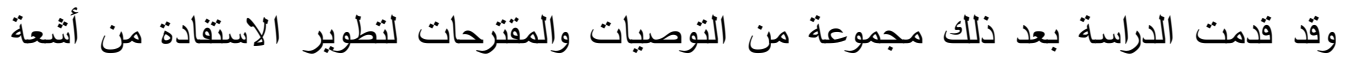

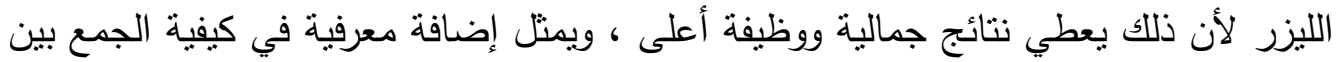

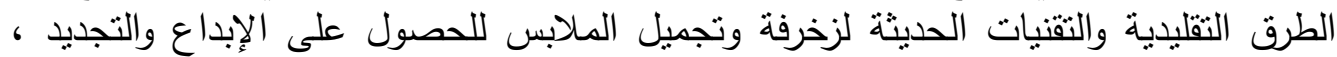

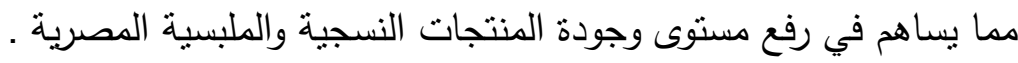




\section{Laser Techniques Effect Aesthetics of Garments}

Prof. Dr.: Mohamed El-badry Abd-Karim, Prof.Dr: Amr Gamal Hassouna, Assis.Dr: Ahmed Mahmoud El-Shaikh, Eng. Ayat Samir Ahmed Abou-RegelaDepartment of Apparel Design \& Technology-Faculty of Applied Arts-Helwan Uni.

\section{Abstract}

The current research aims at conducting a pilot study to demonstrate the effect of laser technology on the aesthetics of ready-made garments as an advanced technique in the methods of engraving, drawing and cutting on raw materials and fabrics as important tools and techniques in shaping and design in order to raise the aesthetic value of the garment product.

In the study, three different types of raw materials were used :( denim- cotton-polyester), (satin- polyester) and (industrial gum), to determine the effect of laser beams on tissue structures and fibers of each material, and their suitability to the accuracy of the resulting sample. Determination of decorative design, identification of variables of the laser machine is the speed and time and strength of the beam and the distance between the beam and the working surface.

After conducting the study samples according to the specific specifications and variables, a series of tests were carried out to determine the level of functional and aesthetic performance of the fabrics produced, as well as conducting a survey to measure the degree of aesthetic value of the proposed samples. These data were then processed statistically through column forms, the thickness of the cloth, the resistance of friction, the permeability of the air and the degree of rigidity of the fabrics, and the suitability of these tests with the effects of cutting, engraving and drawing resulting from laser beams.

\section{The study found the following results:}

1. The physical and mechanical properties of the materials are closely related to the rates of the effects of the lasers.

2. Laser technology has greatly influenced the aesthetics of design, and has introduced new methods to beautify clothing and supplements in general.

The study then presented a set of recommendations for the development of the benefit of laser radiation because it gives aesthetic results and higher function, and is an addition to the knowledge in how to combine traditional methods and modern techniques of decoration and beautification of clothes to obtain creativity and innovation, which contributes to the upgrading and quality of Egyptian textile and clothing products. 


\section{مقدمة ومشكلة البحث :}

تقوم صناعة المنسوجات والملابس الجاهزة بصفة عامة على المعلومة السريعة والمتغيرة في جميع مراحلها، بدءا بالمعلومات الخاصة بأذواق وقدرات المستهلكين وأنشطة

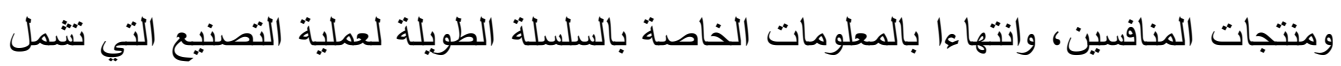
الغزل والنسيج والتجهيز وتصنيع الملابس .

وحول دور البحث العلمي في خدمة القطاعات الصناعية ، وخاصة قطاع الصناعات

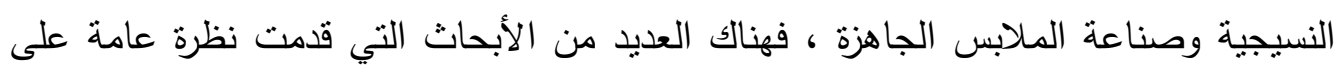

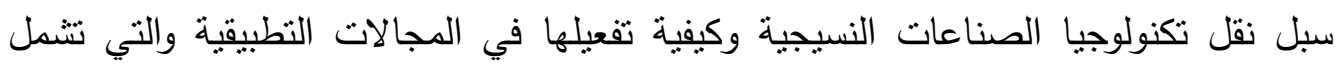
الغزول والمنسوجات الذكية وأساليب الإدارة الحديثة للانتاج ، مثل أبحاث تكنولوجيا الليزر في في في فئي صناعة الملابس الجاهزة ، حيث أنه يجب دراسة طبيعة المنسوجات المستخدمة مع أثنعة

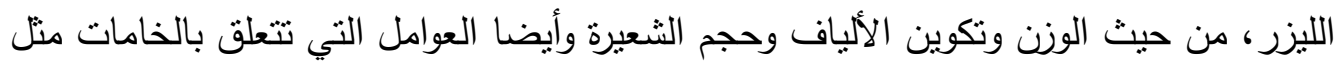

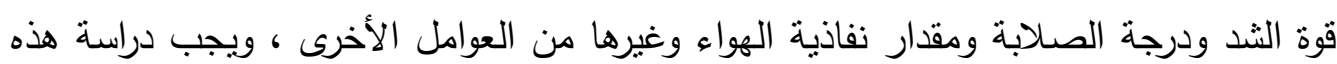
الخامات دراسة جيدة ومدى ملاعمتها لإضفاء تأثنيرات جمالية عليها باستخدام تكنولوجيا الليزر . وبما أن أساس التكنولوجيا هو توسيع اللغات والمفاهيم العامة ، لذلك تم استخدام هذه التكنولوجيا عمليا في مجال تصميم الملابس الجاهزة، لنقام من خلالها معاني جديدة للتعبير عن الأفكار المختلفة في تصميم الأزياء ، باستخدام أساليب تصميمية وتأثنرات مختلفة لماكينة

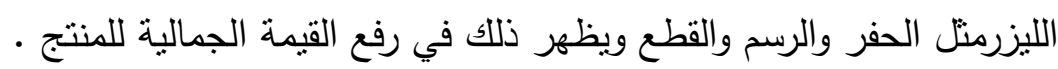
وتتلخص مشكلة البحث في التساؤلات التالية :

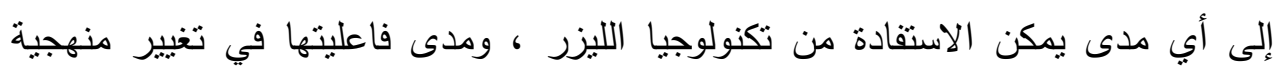

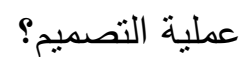

كيف يمكن لتكنولوجيا الليزر أن تتفاعل مع الموضة بصفة بصنة عامة ؟ هل يمكن الوصول إلى تصميمات بمواصفات عالمية وبأقل تكلفة اقتصادية مدكنة

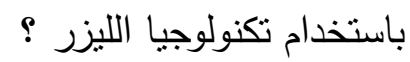
• أثز إدخال الأفكار الجديدة والثقنيات الحديثة لرفع القيم الجمالية بمجال المنسوجات

$$
\text { والملابس ؟ }
$$

أهداف البحث : وابن :

تحليل تأثير تكنولوجيا الليزر على جماليات التصميم • 
معرفة تأثنير أثنعة الليزر على الخواص الطبيعية والميكانيكية للملابس الجاهزة .

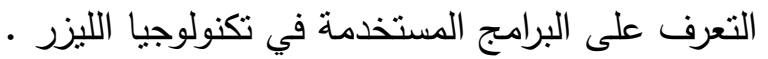
عمل مقارنة في تأثثر الليزر على جميع الخامات المستخدمة وتحليل هذه المقارنة تحليلا علميا . ع توجيه العاملين والقائمين على تكنولوجيا الليزر لكيفية تفعيلها وتطويرها في صناعة فروض البحث : المابس الجاهزة.

وجود فروق دالة إحصائيا لتأثير أشعة الليزر على جماليات التصميم •

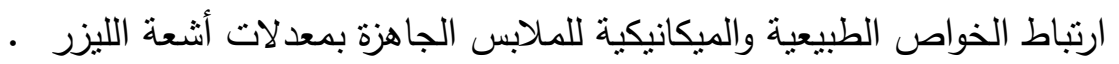

\section{حدود البحث :}

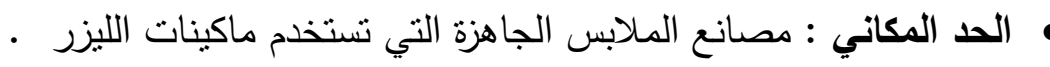

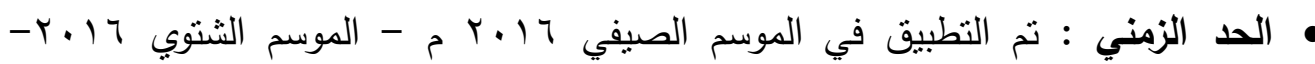

$$
\text { r. IV }
$$

•الحد التقني : تم اختيار خامات ( الجينز - الساتان - الجوخ ) ، واختبار r تقنيات ليزر

$$
\begin{aligned}
& \text { (القطع - الرسم - الحفر ). } \\
& \text { منهج البحث : }
\end{aligned}
$$

يتبع البحث المنهج التجريبي ، وذللك من خلال :

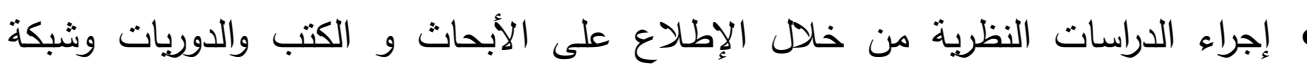

$$
\text { المعلومات . المراء }
$$

إجراء الدراسات التطبيقية عن طريق استخدام تكنولوجيا الليزر مع مجموعة خامات مختلفة

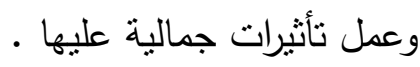

$$
\text { (1) (الدراسات السابقة : (1) }
$$

هذا الجزء يغطي الدراسات السابقة لهذا البحث وهو ينقسم إلى خمس أجزاء : (1-1) ويتتاول ( تكنولوجيا الليزر وعلاقتها بصناعة الملابس الجاهزة ) .. حيث أن استخدام التكنولوجيا المتقدمة في إنتاج الملابس يعطي الفرصة للمنتج أن يكون في مقدمة المنافسة ، ومن أهم المتطلبات الأساسية التي تحدد مرحلة الإعداد للإنتاج ، اختيار الأساليب التكنولوجية 
المتقدمة والتي تحقق أعلى مستوى ممكن من الإنتاجية وأقل معدل استهلاك للمواد الأولية

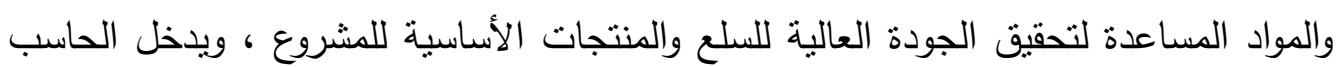

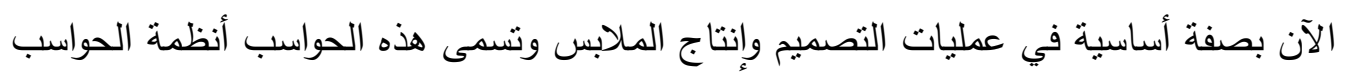

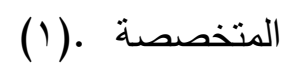

ويرجع استخدام الليزر في صناعة الملابس عالميا إلي عام • ب9 ام ، ونم تطبيقه طبقت

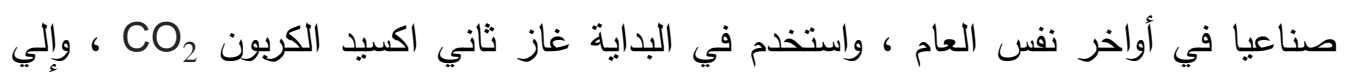

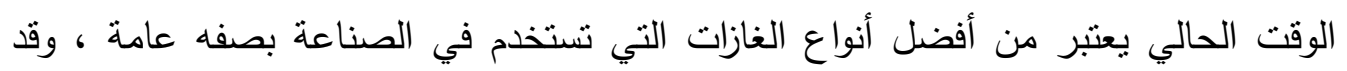
(r). نطور استخدام الليزر بشكل أوسع في الثمانينات ولتبسيط تعريف الليزر ، فأنه جهاز يقوم بالتحكم في كيفية تحرير الذرات للفونونات وهي تلئي

اختصارا للجملة:Light Amplification by Stimulated Emission of Radiation والتي معناها يشرح بالتفصيل فكرة عمل الليزر ، والذي يعتمد على أن الليزر ماهو إلا ضوء مكبر بواسطة عملية تسمى الإنبعاث الإستحناثي للإشعاع وهذا ما قصدنا به التحكم بكيفية

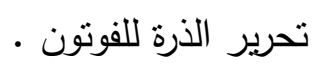

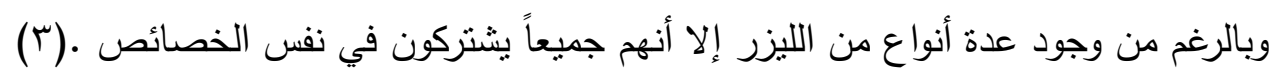

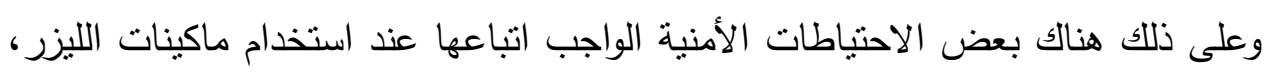
منها : ارتداء النظارات الواقية - وضع علامات التحذير على كل المناطق التي تستخدم الليزر

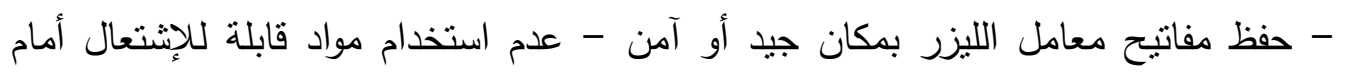

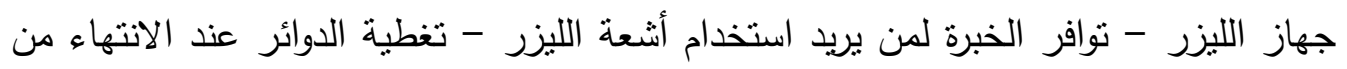

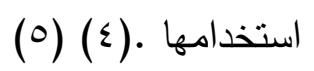

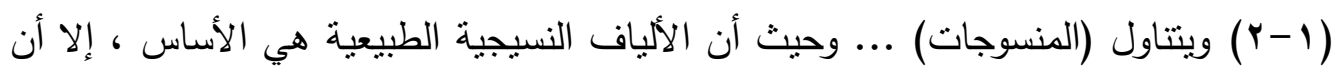

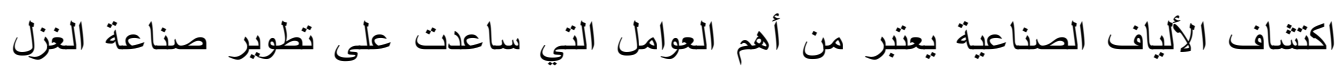

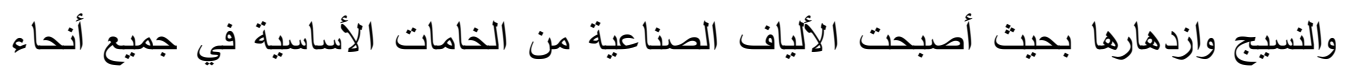

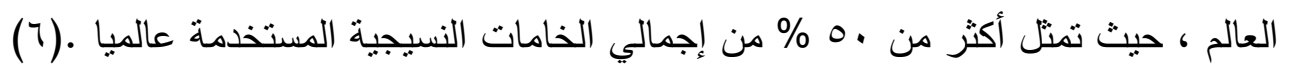
وتتعتبر الألياف من المواد الفريدة في نوعها لسبيين :

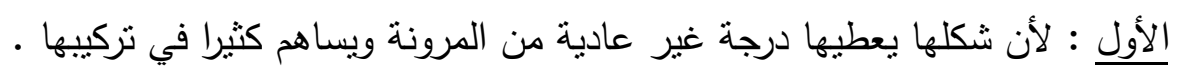

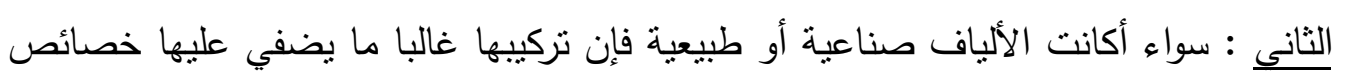
ميكانيكية أفضل عما لو كانت ذات شكل كتل متجمعة . 
ولا تتوقف التكنولوجيا الحديثة في الألياف عند حد استخدامها في صناعة النسيج فقط ، ولكنها امتدت من المناطق التقليدية في النسيج إلى مجالات حديثة ، منل: أعمال التركيبات

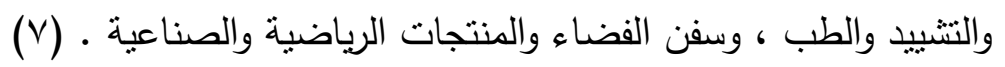
وتعتبر الأقشة المنسوجة أكثر أنواع الأقشة استعمالا وتداولا ، وتتم عملية النسيج ولنيه بتحويل الخيوط المغزولة إلى أقشة تختلف في تركيبها حسب التصميم النسجي وأيضا

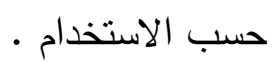

وللأقشة المنسوجة أسس وقواعد علمية وهندسية بنيث على تعاثق خيوط طولية (رأسية) تسمى السداء warp مع خيوط عرضية ( أفقية ) تسمى اللحمة weft في زاوية قائمة ، وينتج عن هذا التعاشق اتجاهات عمودية أو زوايا حادة أو منفرجة ، ويعتبر التركيب النسجي هو أدئ أداة

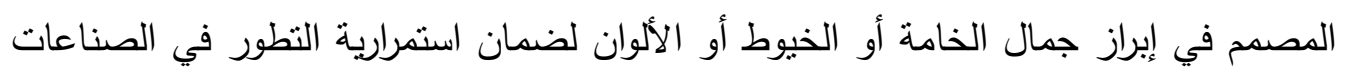

(^). النسيجية

وهذا النوع من الأقمشة ينقسم إلى : أقشة عادية وأقشة شبكية وأقشة وبرية. (9)

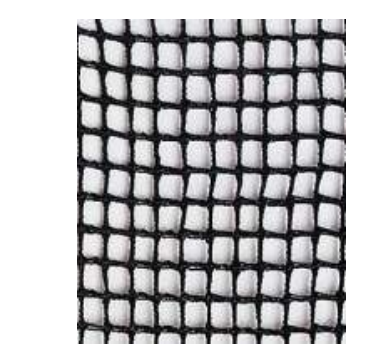

صورة رقم (r) قماش شبكي

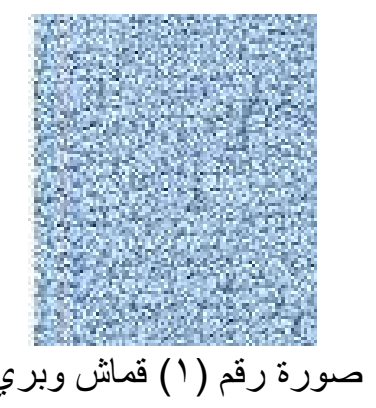

كل هذه الأنواع تتدرج تحت نظام ثابت ، يعرف بالتركيب النسجي ، والذي يؤثر بشكل كبير

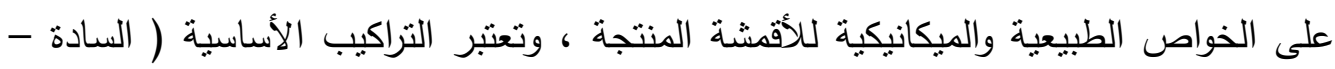

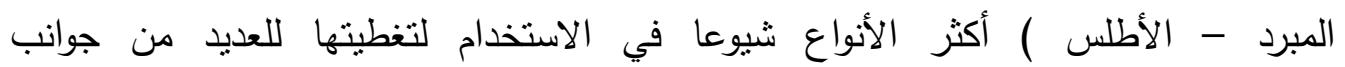
الاحتياجات البشرية . البرد

أما الأقشة الغير منسوجة فهي نوع لا يعتد أساسا في صناعتها على استخدام خيوط

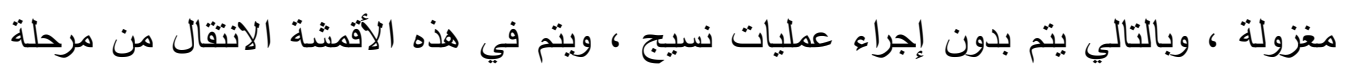

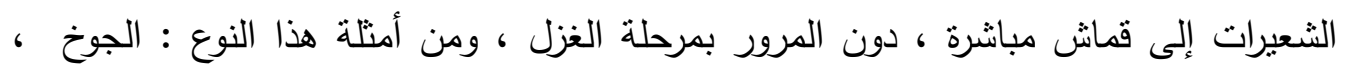

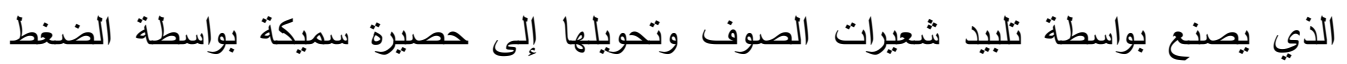
والحرارة والرطوبة . 
أما الأقششة التريكو فهي لا حتاج لأكثر من خيط واحد لصنعه ، حيث يتداخل هذا الخيط

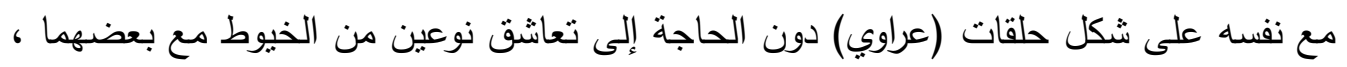
وهو ينقسم إلى نوعين : تريكو سداء - تريكو لحمة . (^) إعلى

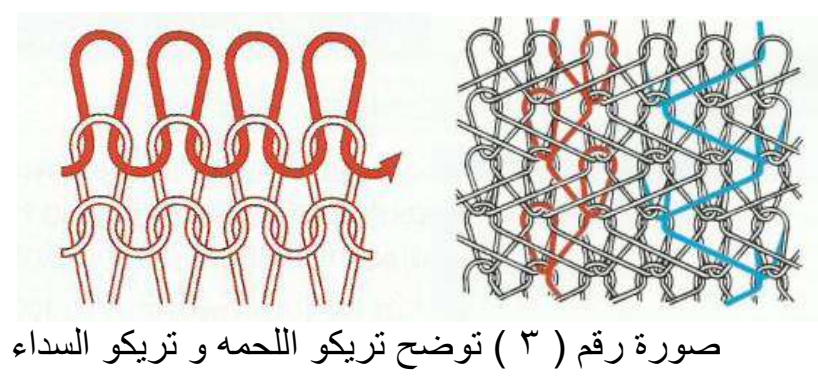

وأما عن التراكيب النسجية ، فيعثبر النسيج السادة هو أبسط أنواع التراكيب النسجية من الناحية التطبيقية ، فمن أمتلته الثنائع استخدامه : الدمور - الفوال - الأورجنزا - الثيفون البوبلين .... والأقششة المنتجة بهذا التركيب تكون أكثر صلابة وليس لها مقاومة عالية للتجعد ، كما أن سطح القماش يكون خشن وذلك لكثرة التقاطعات . ويعتبر النسيج المبردي ثاني أنواع التراكيب استعمالا ، ومن أمتلته : الجبردين - الجينز .

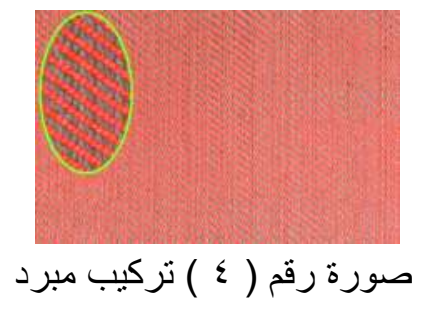

وعادة ما يجعل النسيج المبردي القماش منماسكا منينا عما لو كان مصنوعا مثردئ بطريقة النسيج السادة نتيجة لزيادة عدد الخيوط الداخلية في وحدة التكرار ( البوصة أو السنتيمنر).(• (1) أما النسيج الأطلسي فهو ثالث أنواع التراكيب النسجية البسيطة التي تنكون من سداء واحدة ولحمة واحدة ، ففي التركيب الأطلسي يمكن الحصول على أقششة ذات سطح لامع ناعم

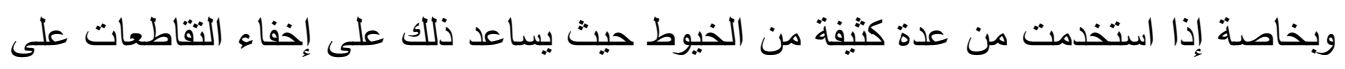
سطح المنسوج ويتيح التركيب الأطلسي إظهار خامات ذات قيمة سواء من السداء أو اللحمة على وجه المنسوج ، ولذلك تم تصنيف أنسجة الأطلس إلى أطلس سداء أو أطلس لحمة. ومن أمثلنه

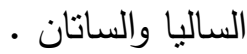




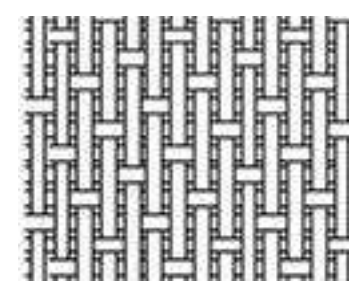

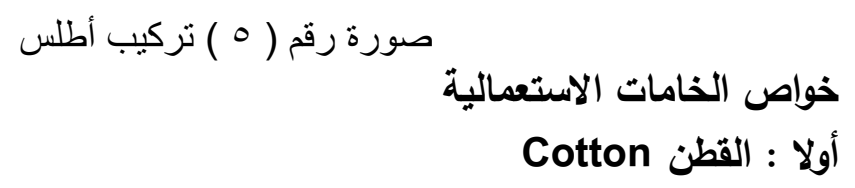

يحتل القطن المركز الرئيسي بين الألياف النسجية في العالم ، فيستهلك منه ضعف

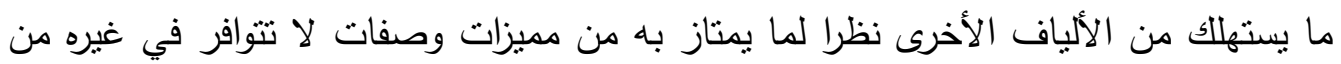
(1) (1) الخامات

المتانة وقوة الثد Tenacity \& Tensile Strength يعتبر القطن منوسط المتانة ، حيث

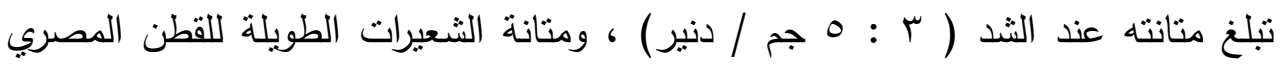

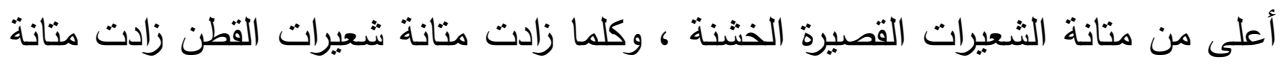

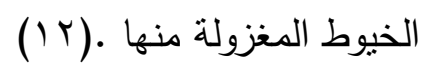
الاستطالة Elongation يعتبر القطن غير سهل الاستطالة نسبيا حيث تبلغ استطالة الشعيرات عند القطع من ( 0 : . (\% ) ) ، ولكنه يعتبر من أفضل الألياف السيليلوزية

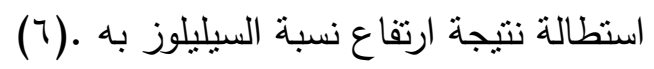
قابلية تكوين الكهرباء الاستاتيكية Static Charge يتميز القطن عن باقي الألياف بقلة

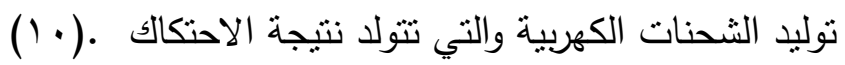

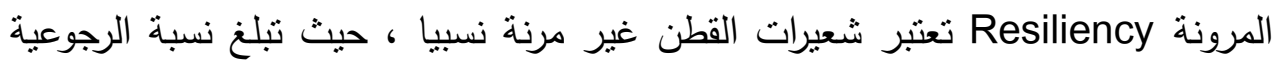

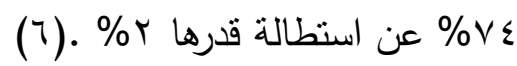
تأثثير الاحتكاك Effect of Abrasion تتميز الأقمشة القطنية بمقاومتها للاحتكاك ، فالقطن لا يفقد متانته بالاحتكاك ويتحمل عمليات الغسيل والعناية المتكررة بدرجة

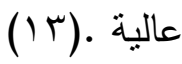
ثانيا :البولي استر Polyester تحتل ألياف البولي استر المرنبة الأولى في الانتاج العالمي مقارنة بالألباف الصناعية

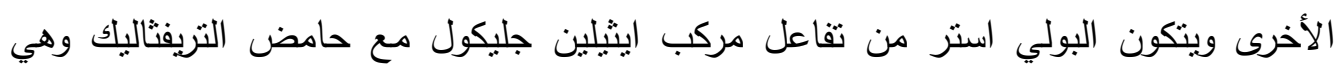

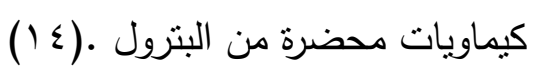


المتانة وقوة الثد Tenacity \& Tensile Strength

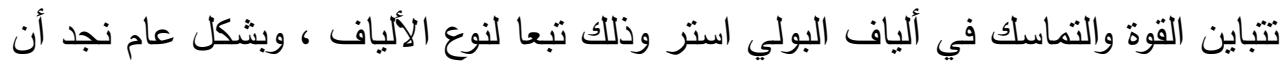

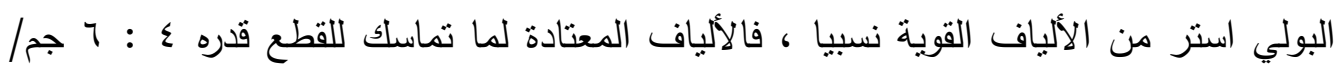

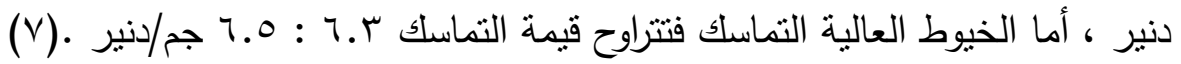

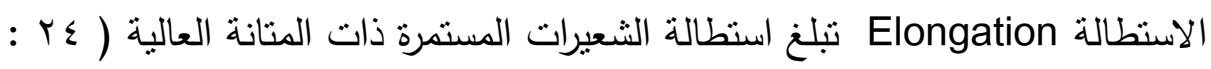

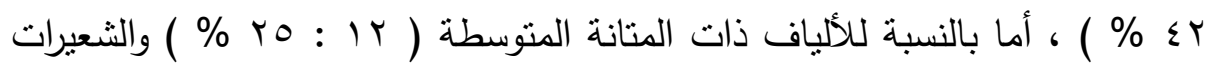

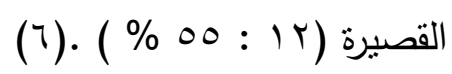

الصلابة Stiffnes تتميز ألياف البولي استر بانخفاض درجة الصلابة مما بساعد

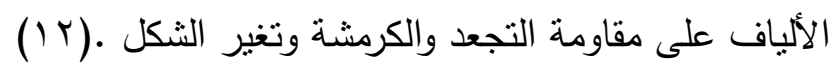

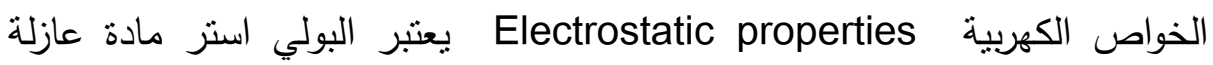
ممتازة وذلك بسبب عدم امتصاص الرطوبة ، ولهذه الخاصية بعض المساوئ منل

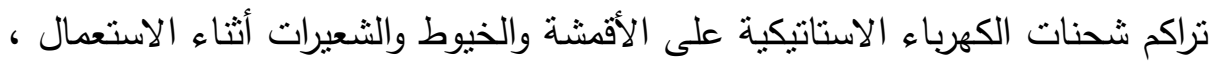

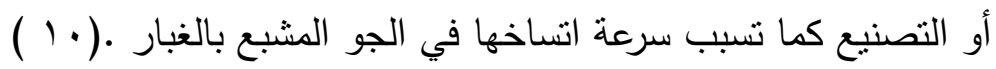
مقاومة الاحتكاك Abrasion Resistance تمتاز ألياف البولي استر بمقاومة باليار عالية

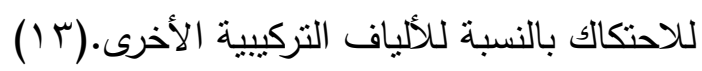

ثالثا :خلط القطن مع البولي استر Cotton - Polyester Blend يخلط القطن مع البولي استر للحصول على أقشة مخلوطة تمثناز بخواص لا تتوافر في

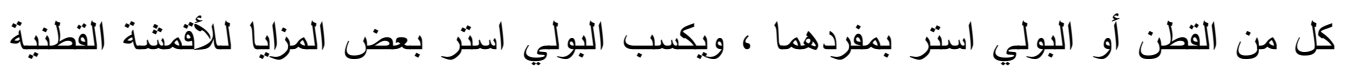

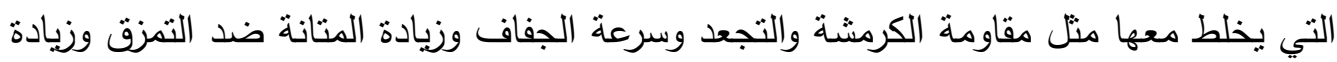

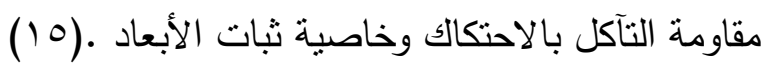

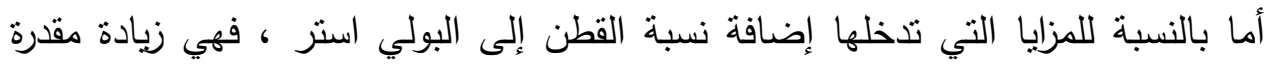

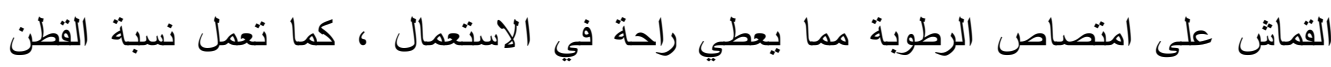

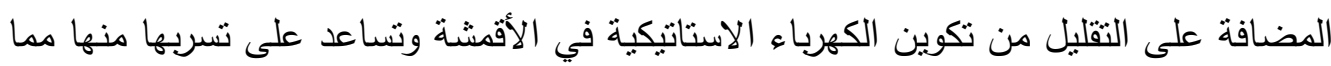

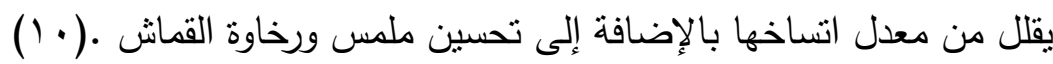

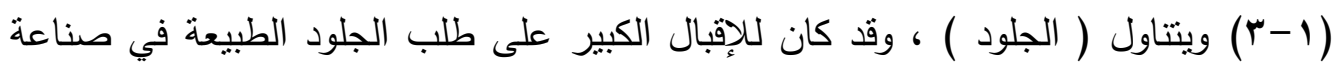

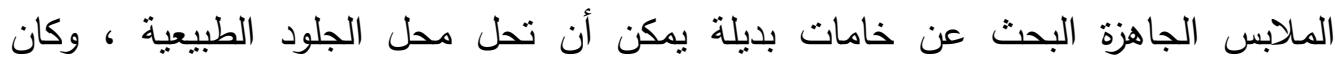

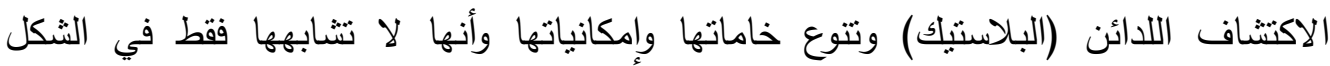
والمظهر بل وتضارعها في صفات المنانة والمرونة وقوة التحمل وقابليتها للثند والثني

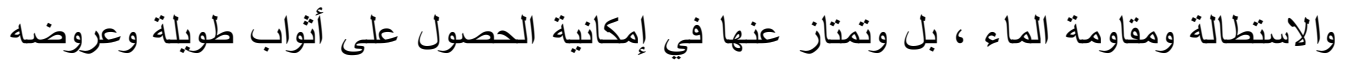


كبيرة ذات شكل وسمك موحد في أي جزء من الأجزاء وهذه مبزة لا تتوفر في الجلد الطبيعي ذو

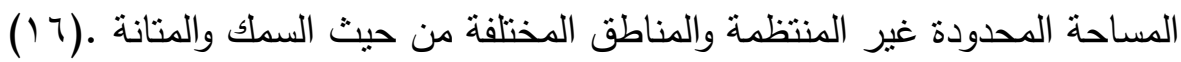

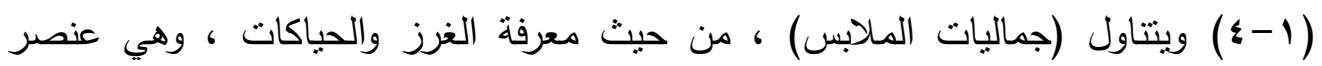

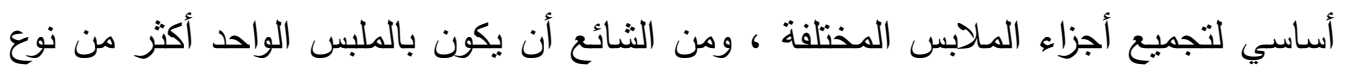
حياكة ، وكل نوع يختلف باختلاف نتوع التطبيقات وباختلاف غرز الحياكة للماكينات المستخدمة لإنتاجه ، وأفضل حياكة هي التي تتمتع بالمظهر المرغوب فيه ، بالإضافة لقلة (IV). التكلفة أما عن المكملات والاكسسوارات ، فيجب أن يجمع التصميم بين العناصر والأسس الفنية

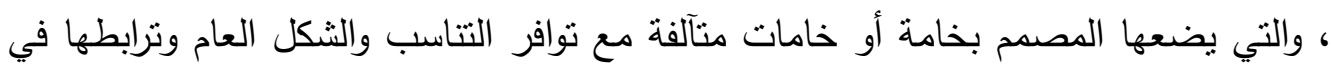
وحدة كلية لنشكل مكمل ما ووظيفته ، ويتضح أن تصميم المكملات يجب أن يراعي فيه أن تتتاسب المكملات مع خطوط الزي ولونه وخامته وأن يراعي المصمم تتسيق الثكل النهائي

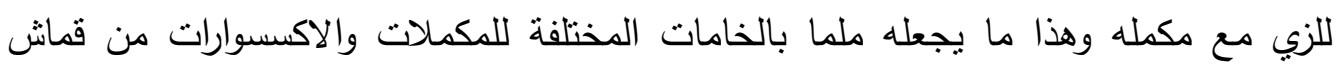

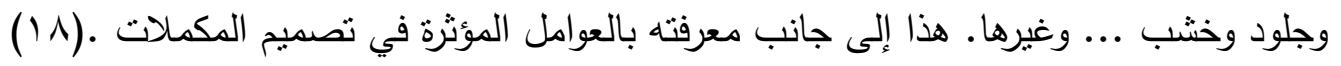

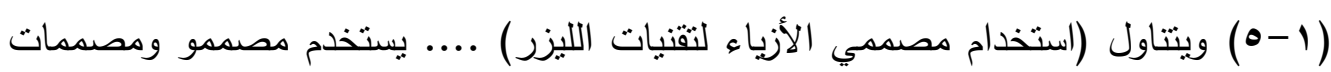

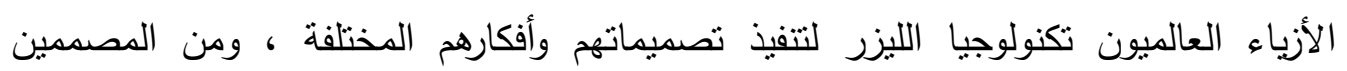
والمصممات الذين استخدمو تكنولوجيا الليزر في القص هم :. Alexander McQueen - Zac Posen - Michael Angel Marchesa

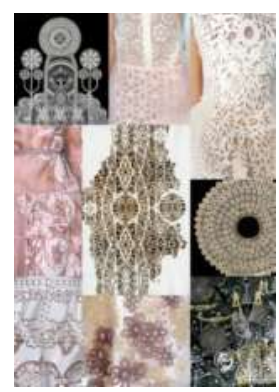

صورة رقم (1) توضح بعض من اتجاهات الموضة اللي استخدمت تقنيات الليزر

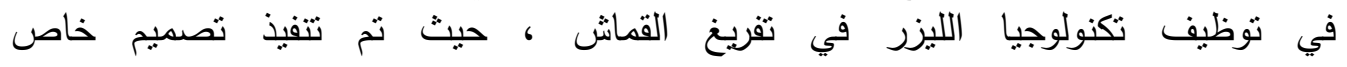
بشركة NIKE وذللك لتفريغ الملابس على ظهر اللاعبين ، وقد تم توظيف هذه المبات الميزة للتخلص

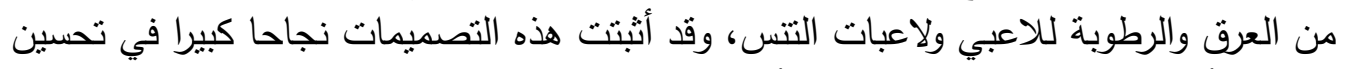

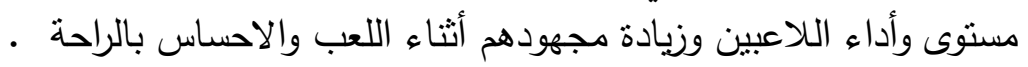




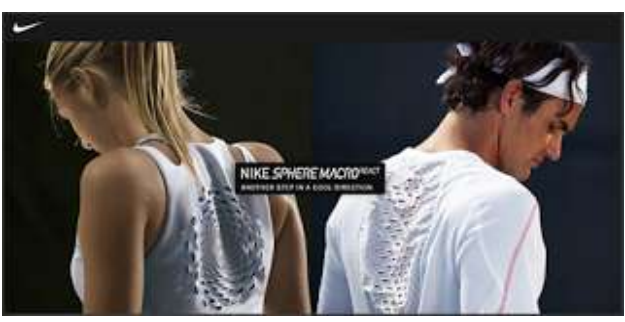

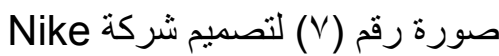

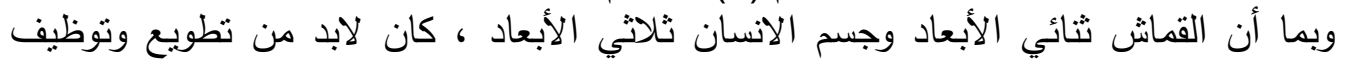

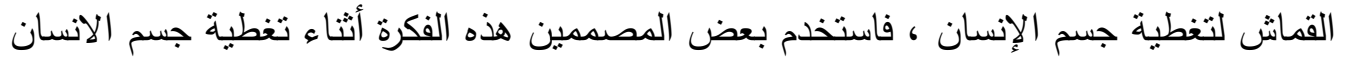

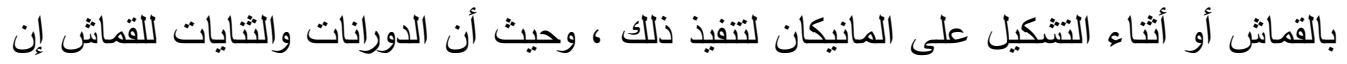

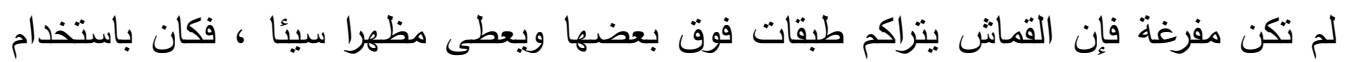

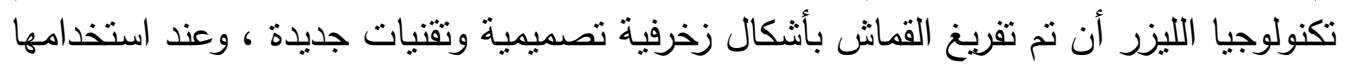

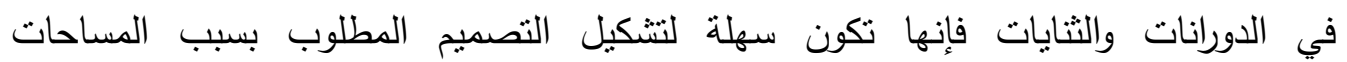

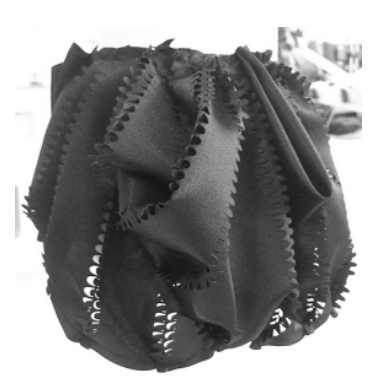

(19). المفرغة النات

صورة رقم (^) لاستخدام تقنيات الليزر في الدورانات و الثنيات

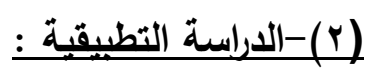

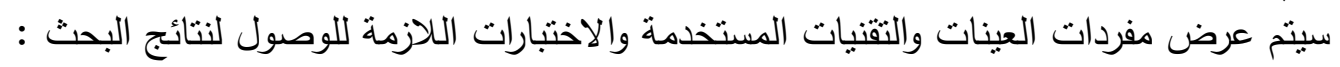

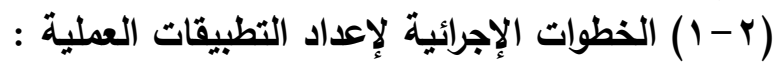
أولا : مرحلة التحليل : الإجطات

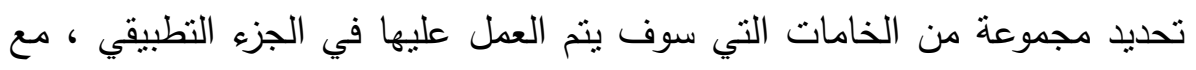

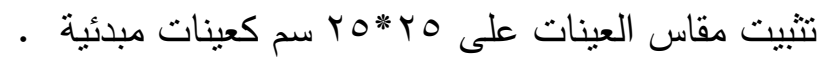

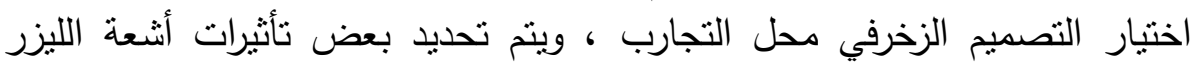

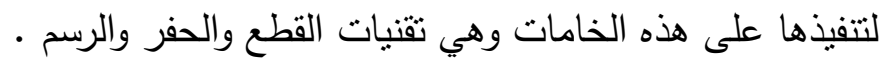

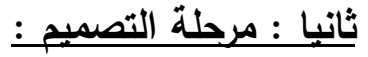

اختيار ماكينة الليزر ، وتحديد مواصفات أشعة الليزر التي تعطي التأثنرات المطلوبة

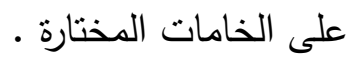
عمل تصميمات زخرفية على برنامج الكوريل درو Corel draw والخاص بتشغيل الماكينة المستخدمة ، لكي توضح التقنيات المختلفة لأشعة الليزر لـات درون 
ثالثا : مرحلة الاختبار والتطبيق : ناتئ

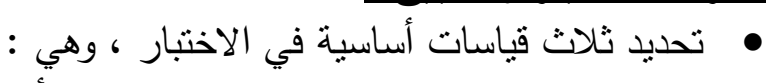

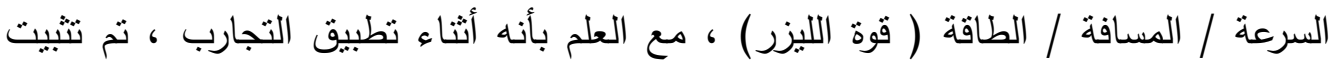

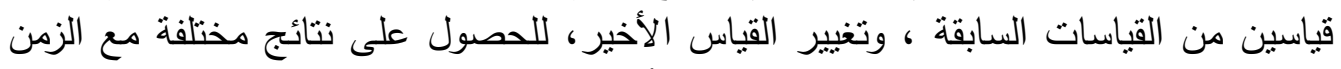

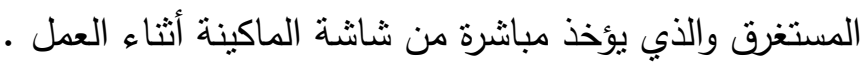
عمل مجموعة اختبارات للخامات ، وقياس المظهرية للعينات محل البحث ل

\section{لايعا : مرحلة التقبيم:}

سينت عمل استمارة تقييم للعينات والوصول لعدة نتائج يتم المقارنة بينها من خلال

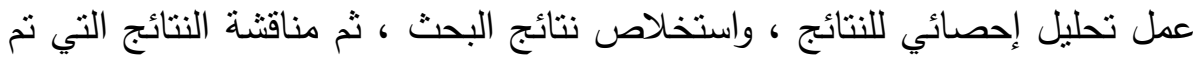

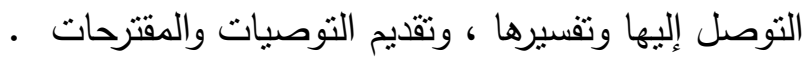

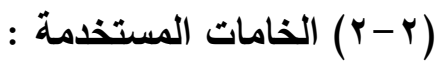

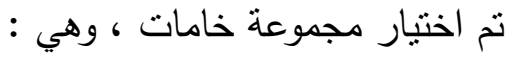

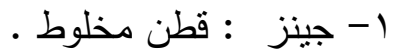

$$
\begin{aligned}
& \text { r- جوخ : شعيرات صوف تم تلبيد ها صناعيا . }
\end{aligned}
$$

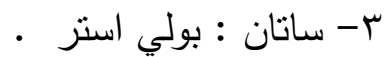

$$
\begin{aligned}
& \text { : التصميم والتقتيات والعينات } \\
& \text { أولا : التصميم الزخرفي : }
\end{aligned}
$$

وهو يتكون من مجموعة من الأشكال العشوائية ، تم تصميمها باتجاه معين ولها مركز ، وتتنشر الأثكال حول المركز ـ فكرة هذا التصميم تعتمد على كيفية قص حدود موديل أو باترون

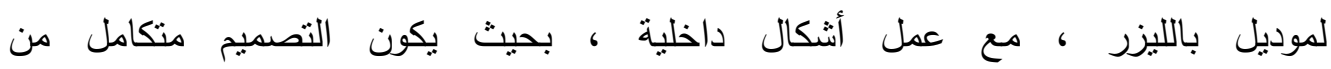

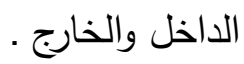

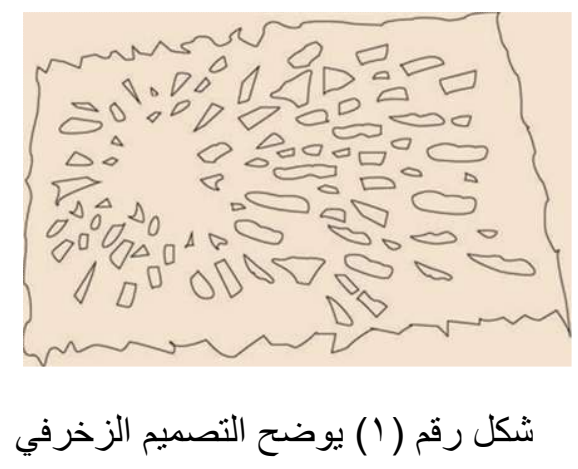

ثانيا : تقتيات الليزر والماكينة المستخدمة : 1-التقتيات : لتحقيق القيمة الجمالية من تتفيذ التصميم السابق ذكره ، تم استخدام ثلاث تقنيات لتتفيذها بأنعة الليزر وهي الحفر والقطع والرسم على الخامات ، وهذه التقنيات 
تعتمد على عدد من العناصر المهمة التي يجب دراستها جيدا ، وهذه العناصر هي

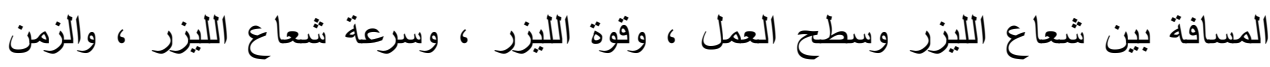
المستغرق لعمل هذه التقنية ـ r-ماكينة الليزر المستخدمة :

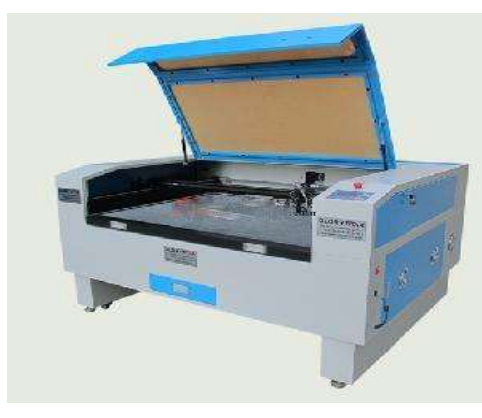

صورة رقم ( 9 ) نوضح ماكينة الليزر GLC-1680 المستخدمة

والجدول التالي رقم ( ) يوضح مواصفات ماكينة الليزر المستخدمة :

\begin{tabular}{|c|c|}
\hline Model & GLC-1680 \\
\hline Laser type & domestic-made $\mathrm{CO} 2$ laser tube \\
\hline Laser power & $80 w$ \\
\hline Working area & $1600 \times 800 \mathrm{~mm}$ \\
\hline Engraving speed & $0-1500 \mathrm{~mm} / \mathrm{s}$ \\
\hline Cutting speed & $0-800 \mathrm{~mm} / \mathrm{s}$ \\
\hline Cooling mode & Water-cooling and protection system \\
\hline Gross power & $1500 w$ \\
\hline Working voltage & $220 \pm 10 \% 50 \mathrm{~Hz}$ \\
\hline Operating temperature & $0 \sim 45^{\circ} \mathrm{C}$ \\
\hline Controlling software & Glory star laser software \\
\hline Gross weight & $560 K G$ \\
\hline
\end{tabular}

ثالثا : تصميم توصيف للعينات المقترحة في البحث : في سبيل تحقيق نتائج تقنيات الليزر على الخامات المختلفة المختارة محل الدراسة وإيضاح القيم الجمالية من حيث الدقة والسرعة ، تم اختيار بعض العينات لإجراء التجارب علبها ، 
والجدول التالي رقم (Y) يوضح توصيف عينات البحث من خلال اختبار الخامات والتقنيات

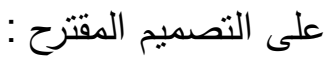

\begin{tabular}{|c|c|c|c|}
\hline التقنيات & الخامات & الترقيم & م \\
\hline رسم & \multirow{3}{*}{ جينز } & $1-1$ & 1 \\
\hline حفر & & $r-1$ & $T$ \\
\hline قطع & & $r-1$ & $r$ \\
\hline رسم & \multirow{3}{*}{ جوخ } & $1-r$ & $\varepsilon$ \\
\hline حفر & & Y-Y & 0 \\
\hline قطع & & $r-r$ & 7 \\
\hline رسم & \multirow{3}{*}{ ساتان } & $1-r$ & V \\
\hline حفر & & T-r & $\Lambda$ \\
\hline قطع & & $r-r$ & 9 \\
\hline
\end{tabular}

\section{جدول رقم (r) يوضح توصيف عينات البحث}

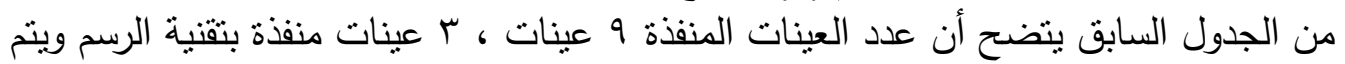

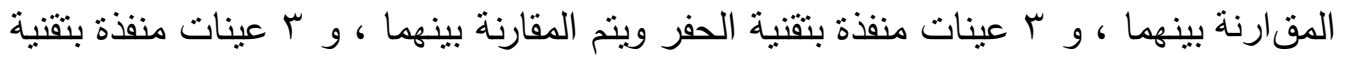

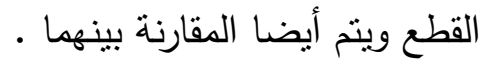

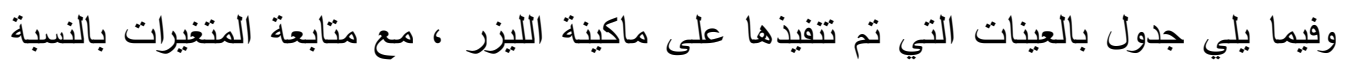

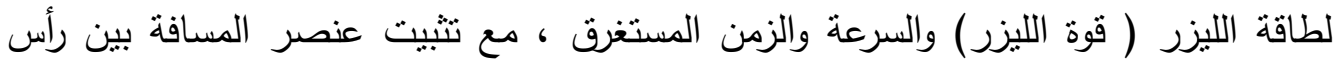
الليزر وسطح العمل مع جميع الخامات 1.0 سم ، والجدول التالي رقم (r) يشرح هذه العينات

\begin{tabular}{|c|c|c|c|c|c|c|c|}
\hline العينات & الزمن & الطاقة & السرعة & التقتيات & الخامات & الترقيم & p \\
\hline & $\begin{array}{l}1.44 \\
\min \end{array}$ & $\begin{array}{c}9 / 13 \\
w\end{array}$ & $\begin{array}{c}5 \\
\mathrm{~mm} / \mathrm{s}\end{array}$ & رسم & \multirow{2}{*}{ جينز } & $1-1$ & 1 \\
\hline & $\begin{array}{l}1.25 \\
\min \end{array}$ & $\begin{array}{c}13 / 15 \\
w\end{array}$ & $\begin{array}{c}8 \\
\mathrm{~mm} / \mathrm{s}\end{array}$ & حفر & & $r_{-1}$ & r \\
\hline
\end{tabular}




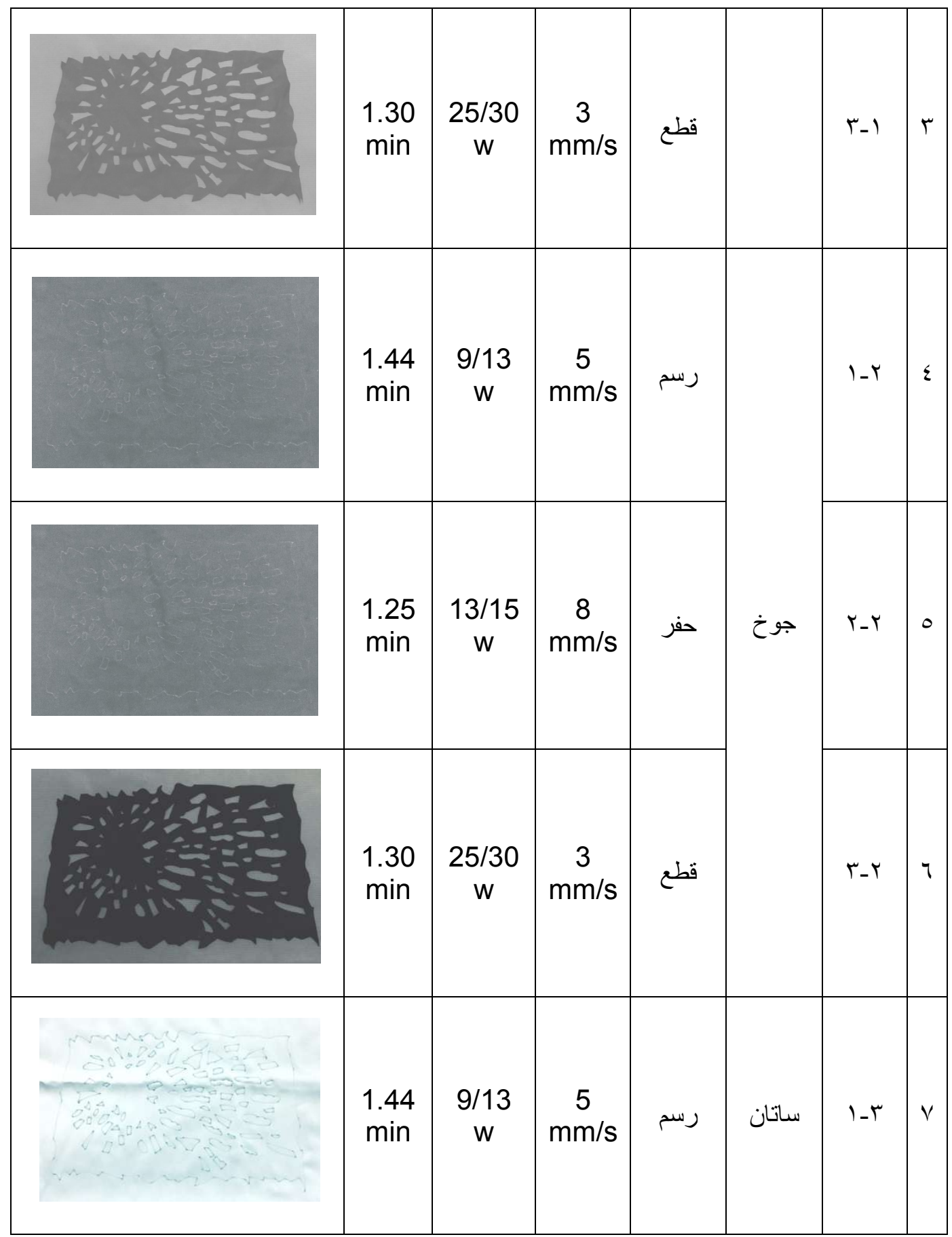




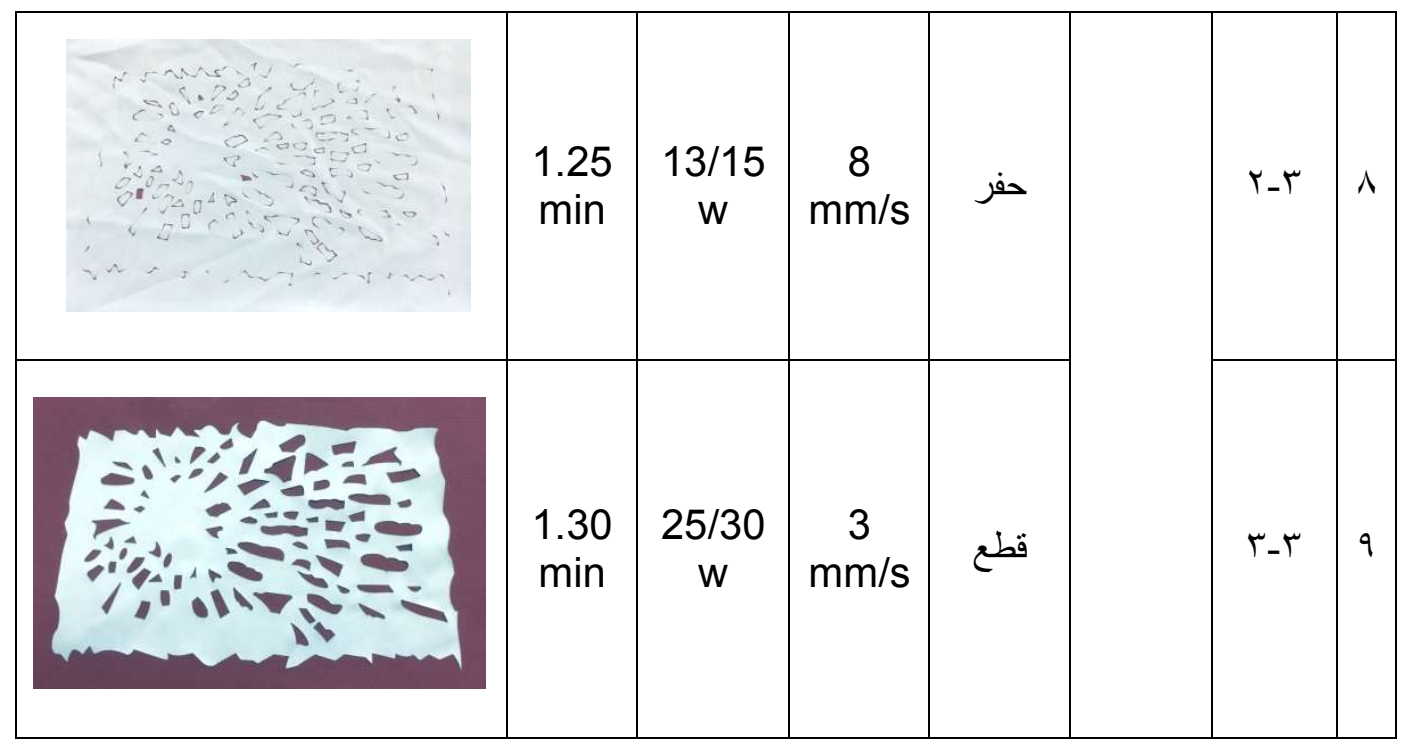

جدول رقم (ץ) يشرح متغيرات العينات ( من حيث السرعة والمسافة والزمن ) : (الاختبارات

هناك نوعين من الاختبارات ، يتم استخدامها لقياس درجة دقة العينات محل التجربة ، كالآتي :

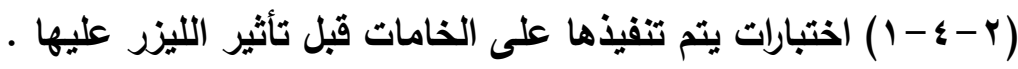
تم إجراء الاختبارات المعملية بالمركز القومي البحوث بالقاهرة ، طبقا للجو القياسي لاختبارات

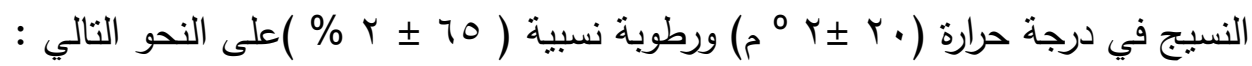

\section{Air permeability اختبار نفاذية الهواء}

تم إجراء هذا الاختبار باستخدام جهاز نفاذية الهواء وذللك طبقا للمواصفة القياسية : ASTM D737 - 04(2008) e1 Standard Test Method for Air Permeability of Textile Fabrics.

\section{Fabric Stiffness r ختبار تقدير الصلابة}

تم إجراء هذا الاختبار باستخدام جهاز قياس درجة الصلابة وذلك طبقا للمواصفة القياسية : ASTM D1388 - 08 Standard Test Method for Stiffness of Fabrics.

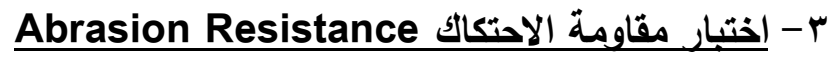

تم إجراء هذا الاختبار باستخدام جهاز مقامة الاحتكالك وذللك طبقا للمواصفة القياسية : ASTM D3885 - 07a Standard Test Method for Abrasion Resistance of Textile Fabrics.

ع - اختبار قوة الثد والاستطالة Tensile Strength and Elongation 
تم إجراء هذا الاختبار باستخدام جهاز قوة الثد والاستطالة وذلك طبقا للمواصفة القياسية : ASTM D5035 - 06(2008) el Standard Test Method for Breaking Force and Elongation of Textile Fabrics.

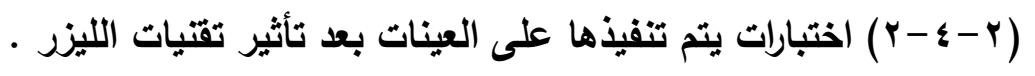

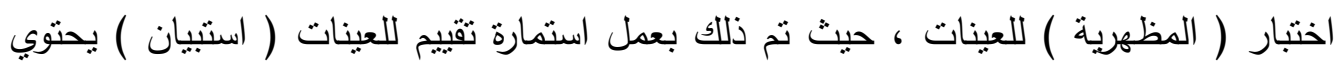

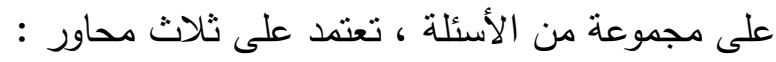
المحور الأول : الجانب الوظيفي مني

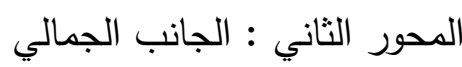

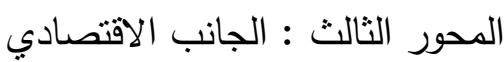
: النتائج والمناقثنة : بعد إنتاج عينات البحث واختبارها معمليا طبقا للجو القياسي ، تم تسجيل النتائج التي نم

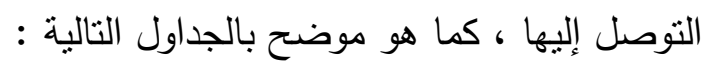

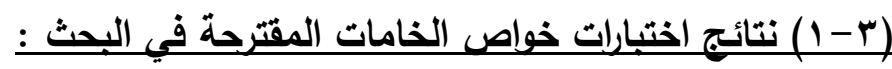
1- نتائج تأثير التركيب النسجي على نفاذية الهواء الجدول التالي رقم (ع) يوضح نتائج تأثنر التركيب النسجي على نفاذية الهواء باستخدام

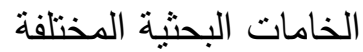

\begin{tabular}{|c|c|c|c|c|}
\hline نفاذية الهواء & نوع الألياف & التركيب النسجي & اسم الخامة & م \\
\hline $1 . . r$. & قطن مخلوط & مبرد // 1/ & جينز & 1 \\
\hline 纟.9. & صوف & صوف ملبد صناعيا & جوخ & r \\
\hline $19 . \varepsilon$. & بولي اسنز & أطلس & ساتان & $r$ \\
\hline
\end{tabular}

يتضح من الجدول ( ) أن التركيب النسجي لخامة الجوخ حقق أقل معدل لنفاذية الهواء وكان

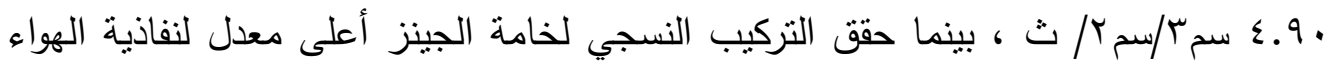

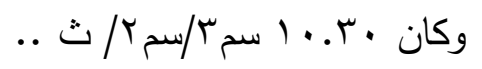

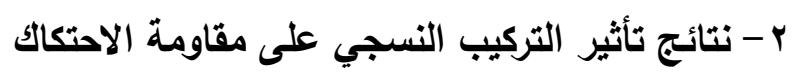

الجدول التالي رقم (0) يوضح نتائج تأثير التركيب النسجي على مقاومة الاحتكاك باستخدام

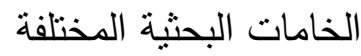




\begin{tabular}{|c|c|c|c|c|}
\hline مقاومة الاحتكالك & نوع الألياف & التركيب النسجي & اسم الخامة & ? \\
\hline $1 . r r$ & قطن مخلوط & مبرد س// & جينز & 1 \\
\hline r... & صوف & صوف ملبد صناعيا & جوخ & $r$ \\
\hline Tイヘ.T & بولي استر & أطلس ^ & 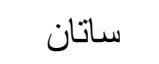 & r \\
\hline
\end{tabular}

يتضح من الجدول (0) أن التركيب النسجي لخامة الجوخ حقق أعلى معدل لمقاومة الاحتكالك

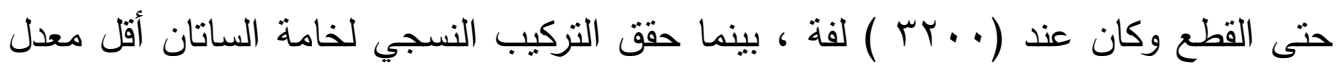

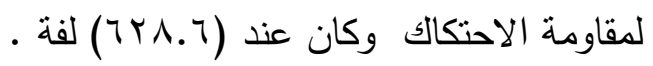

\section{r- نتائج تأثير التركيب النسجي على درجة الصنابة الصنابة}

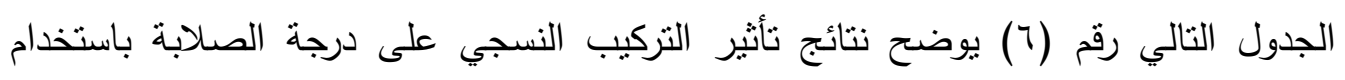

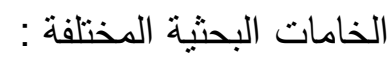

\begin{tabular}{|c|c|c|c|c|}
\hline درجة الصلابة & نوع الألياف & التركيب النسجي & اسم الخامة & ? \\
\hline $1 \leqslant \pi$ & قطن مخلوط & مبرد س// & جينز & 1 \\
\hline$r \cdot \leq \leqslant$ & صوف & صوف ملبد صناعيا & جوخ & $r$ \\
\hline$V V^{\prime}$ & بولي استر & أطلس & ساتان & $r$ \\
\hline
\end{tabular}

يتضح من الجدول (؟) أن التركيب النسجي لخامة الجوخ حقق أعلى درجة صلابة وكانت

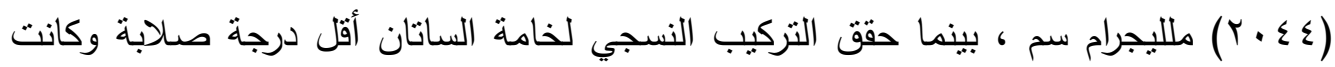

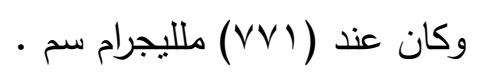

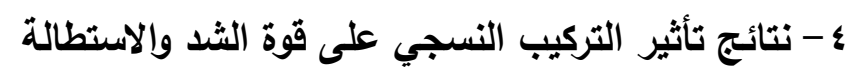

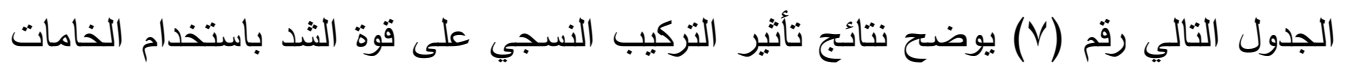
البحثية المختلفة

\begin{tabular}{|c|c|c|c|c|c|}
\hline الاستطالة(\%) & (كجم/قوة) & نوع الألياف & التركيب النسجي & اسم الخامة & م \\
\hline$\leq 7$ & TV & قطن مخلوط & مبرد س// & جينز & 1 \\
\hline$\leqslant V .0$ & $V \varepsilon$ & صوف & صناعيا ملبد & جوخ & r \\
\hline$\leq 0$ & 70 & بولي استر & أطلس & ساتان & r \\
\hline
\end{tabular}


يتضح من الجدول (V) أن التركيب النسجي لخامة الجوخ حقق أعلى درجة لقوة الثد وكانت

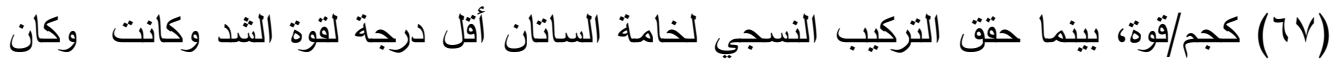
عند (70) كجم/قوة .

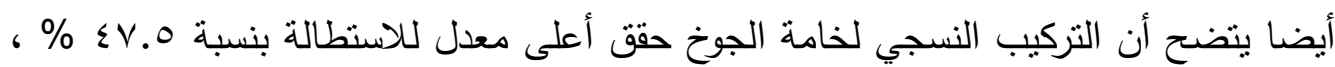

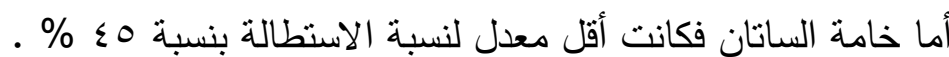
: بائج

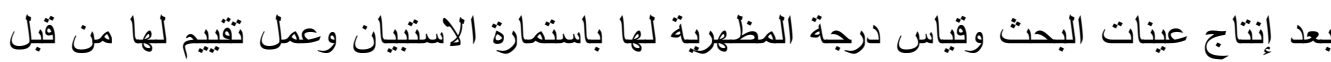
المحكمين ، تم تسجيل النتائج التي تم التوصل إليها ومعالجتها إحصائيا كما هو موضح

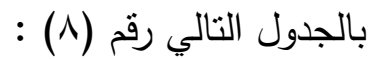

\begin{tabular}{|c|c|c|c|}
\hline درجة المظهرية (من الاستبيان) \% & وصف العينة & ترقيم العينة & p \\
\hline$\% 70$ & تقنية الرسم على خامة الجينز & $1-1$ & 1 \\
\hline$\% \varepsilon$. & تقنية الحفر على خامة الجينز & $r-1$ & r \\
\hline$\% \vee$. & تقنية القطع على خامة الجينز & $r-1$ & r \\
\hline$\% 4$. & تقنية الرسم على خامة الجوخ & $1-r$ & $\varepsilon$ \\
\hline$\% \vee 0$ & تقنية الحفر على خامة الجوخ & $r-r$ & 0 \\
\hline$\% \wedge r$ & تقنية القطع على خامة الجوخ & $r-r$ & 7 \\
\hline$\% \leq r$ & تقنية الرسم على خامة الساتان & $1-r$ & 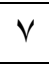 \\
\hline$\% \leqslant 0$ & تقنية الحفر على خامة الساتان & $r-r$ & $\Lambda$ \\
\hline$\% \wedge$. & تقنية القطع على خامة الساتان & $r-r$ & 9 \\
\hline
\end{tabular}

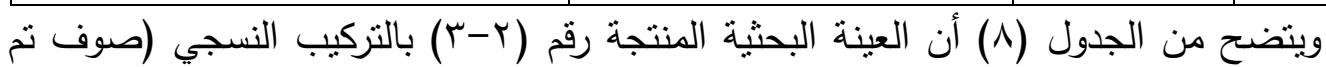

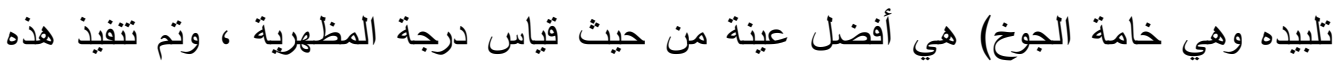

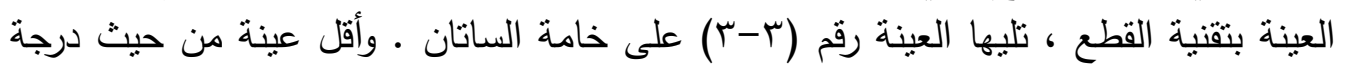

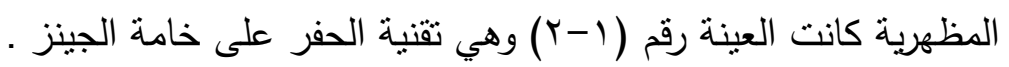
:

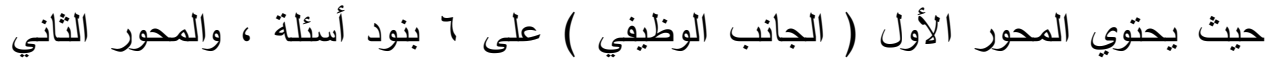

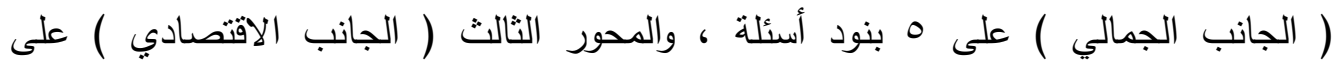

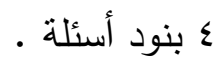

وقد تم وضع خمس مستويات للإجابة عن الأسئلة وهى : (موافق جدا - موافق - إلى حد ما غير موافق - غير موافق مطلقا ) ولحساب نسبة إجابات المحكمين على المحاور الثلاثية وضعت المعايير الآتية : مواتئ

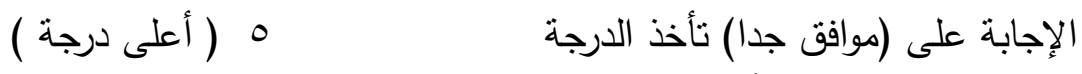

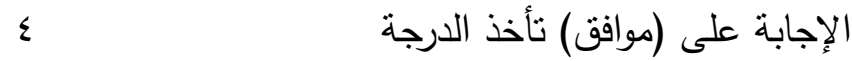




$$
\begin{aligned}
& \text { r } \\
& \text { الإجابة على (إلى حد ما) تأخذ الدرجة } \\
& \text { r } \\
& \text { الإجابة على (غير موافق) تأخذ الدرجة الإنة }
\end{aligned}
$$

وتمت الدراسة الإحصائية على 10 محكم من المتخصصين الأكاديميين ورجال الصناعة

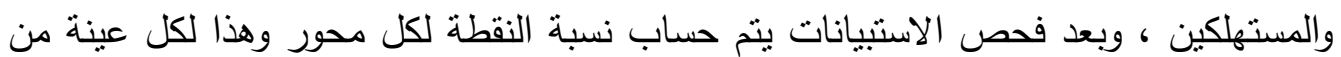

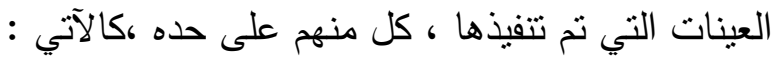
نسبة النقطة لكل محور

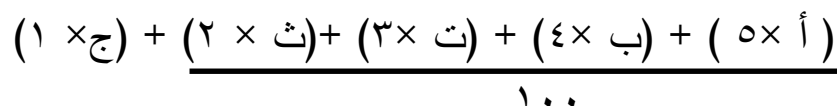

\begin{tabular}{|c|c|c|c|c|c|c|c|c|}
\hline \multirow[b]{2}{*}{ النسبة } & \multirow{2}{*}{ الاجمالد } & \multicolumn{5}{|c|}{ درجة المو افقة ( عدد المحكين) } & \multirow[b]{2}{*}{ البنود } & \multirow[b]{2}{*}{ c } \\
\hline & & 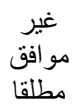 & 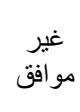 & 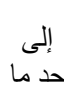 & موافق & 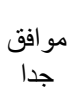 & & \\
\hline$\%$ «^ & 10 & r & r & r & r & $\varepsilon$ & تأثئر أثشعة الليزر على تلف الخامة & 1 \\
\hline$\%$ \&0 & 10 & v & - & r & - & ० & 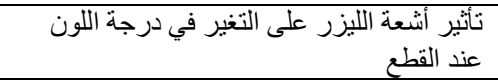 & r \\
\hline$\%$ TV & 10 & 1 & 1 & r & 0 & v & 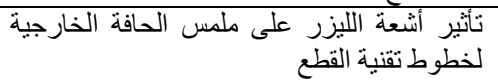 & r \\
\hline$\% \circ \mathrm{V}$ & 10 & 1 & $r$ & $r$ & $r$ & $\mathrm{~V}$ & الكنتج بعد الاستخذام يؤدي وظيفتنه بدرجة مقبولة & $\varepsilon$ \\
\hline$\%^{r}$. & 10 & $\mathrm{v}$ & $\varepsilon$ & r & 1 & 1 & مرطية إنثي حد كبيرة الليزر في تقنية الحفر نتيجة & . \\
\hline$\%$ or & 10 & r & 1 & r & r & 1 & 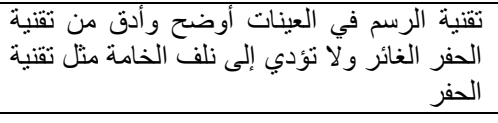 & 1 \\
\hline
\end{tabular}

عدد المحكمين × أعلى درجة حيث أن:

أ= ( موافق جدا )، ب= (موافق )، ت = (إلى حد ما) ، ث = (غير موافق) ، ج = (غير

موافق مطلقا) أولا : من حيث الجانب الوظيفي: الجدول التالي رقم (9) يوضح أراء المحكمين ونسبة تقييم كل محور :

من خلال الجدول السابق رقم (9) يتضح لنا آراء المحكمين من الناحية الوظيفية ،وعدد هؤلاء

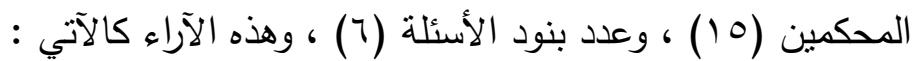

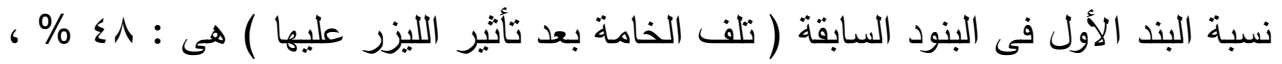
أي أنها نسبة قليلة ، وتتضح أنها كانت مع الخامات ذات التهات التركيب النسجي الأقل في

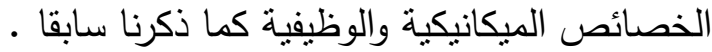


نسبة البند الثاني ( التغير في درجة اللون عند القطع )هي : 0؛ \% ، وكانت من الخامات

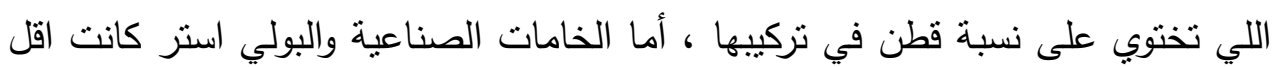

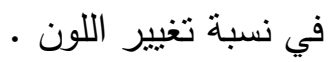

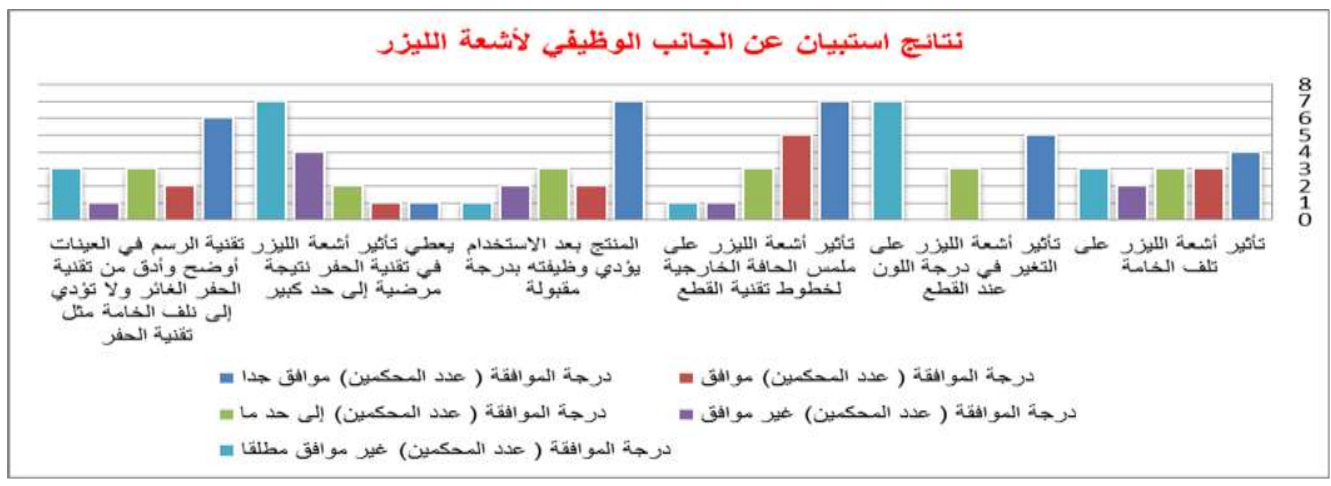

نسبة البند الثالث ( تأثثر حواف القطع ) هي : VT٪\% ، وكانت في الخامات التي تحتوي على نسبة قطن في تركيبها ، أما الخامات البولي استر كانت ادق والحواف كانت أكثر

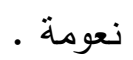

نسبة البند الرابع ( وظيفة المنتج بعد تأثثر الليزر ) هي : Vov ، بعد اتباع طرق العناية

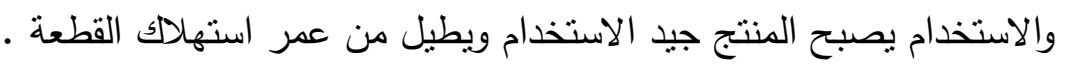

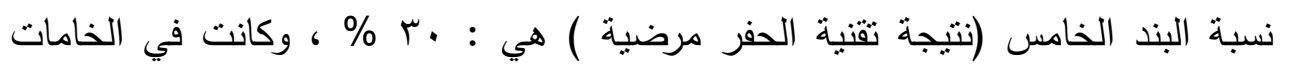

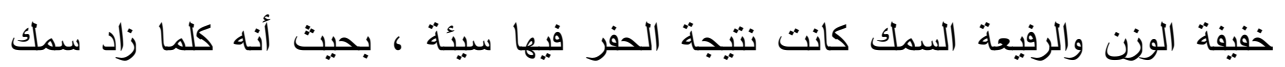

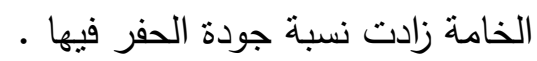

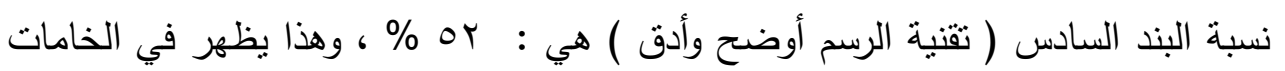

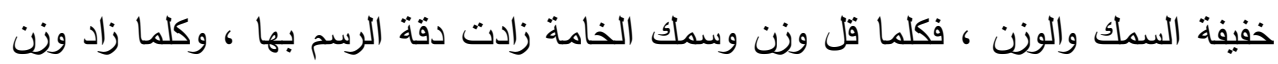
وسمك الخامة ، كانت تقنية الحفر أدق كقن 


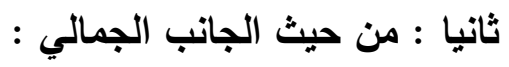

الجدول التالي رقم (• (1) يوضح أراء المحكمين ونسبة تقييم كل محور :

\begin{tabular}{|c|c|c|c|c|c|c|c|c|c|}
\hline \multirow[b]{2}{*}{ 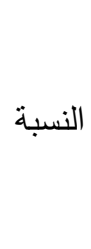 } & \multirow[b]{2}{*}{ 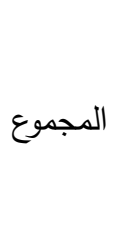 } & \multicolumn{5}{|c|}{ درجة الموافقة (عدد المحكمين ) } & \multirow[b]{2}{*}{ 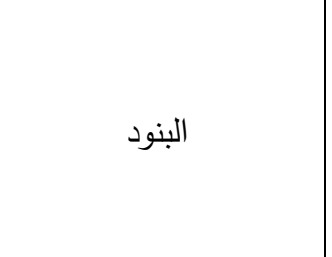 } & \multirow[b]{2}{*}{ ? } & \\
\hline & & موافير & غوافق & 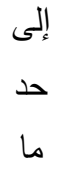 & 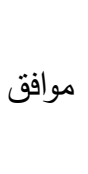 & هوافق & & & \\
\hline$\% \circ \wedge$ & 10 & $r$ & $r$ & $r$ & $r$ & 0 & 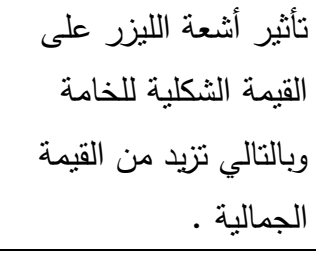 & 1 & \\
\hline \%т4 & 10 & . & 1 & $r$ & $r$ & $\wedge$ & 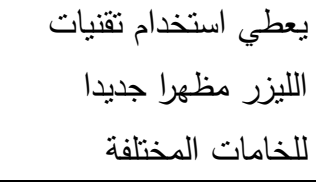 & $r$ & $\begin{array}{l}\overline{\bar{y}} . \\
\bar{y} .\end{array}$ \\
\hline$\% 00$ & 10 & $r$ & 1 & r & $\varepsilon$ & 0 & الناماسبة أنثعة الليزر مع النسبة & $r$ & $\eta_{:}$ \\
\hline$\% \circ 9$ & 10 & 1 & 1 & $r$ & 0 & 1 & 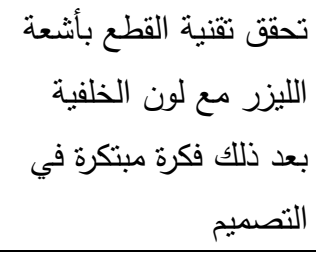 & $\varepsilon$ & \\
\hline$\% \leq 7$ & 10 & $r$ & $r$ & $\varepsilon$ & $r$ & $r$ & تقنية اشعة الليزر والخامة ترابط وانسجام بين & 0 & \\
\hline
\end{tabular}

من خلال الجدول السابق رقم (• (1) يتضح لنا آراء المحكمين من الناحية الجمالية ، وعدد هؤلاء المحكمين (0 1) ، وعدد بنود الأسئلة (0) ، وهذه الآراء كالآتي :

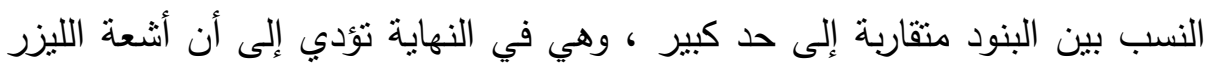
أضافت نسبة كبيرة من الجمالية في العينات ، مع اختلاف الخامات والتقنيات . نسبة الجمال في عينات القطع أكثر من نسبة الجمال في عينات الحفر

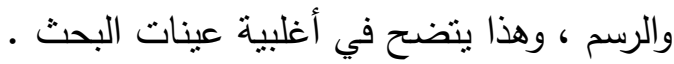


تقنية القطع تعطي ابتكارا واستحداثا لأفكار تصميمية عديدة وخصوصا مع لون الخلفية المضاف لها ، وهو ما يتضح من النسبة وه \% و الناتجة في البند

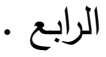

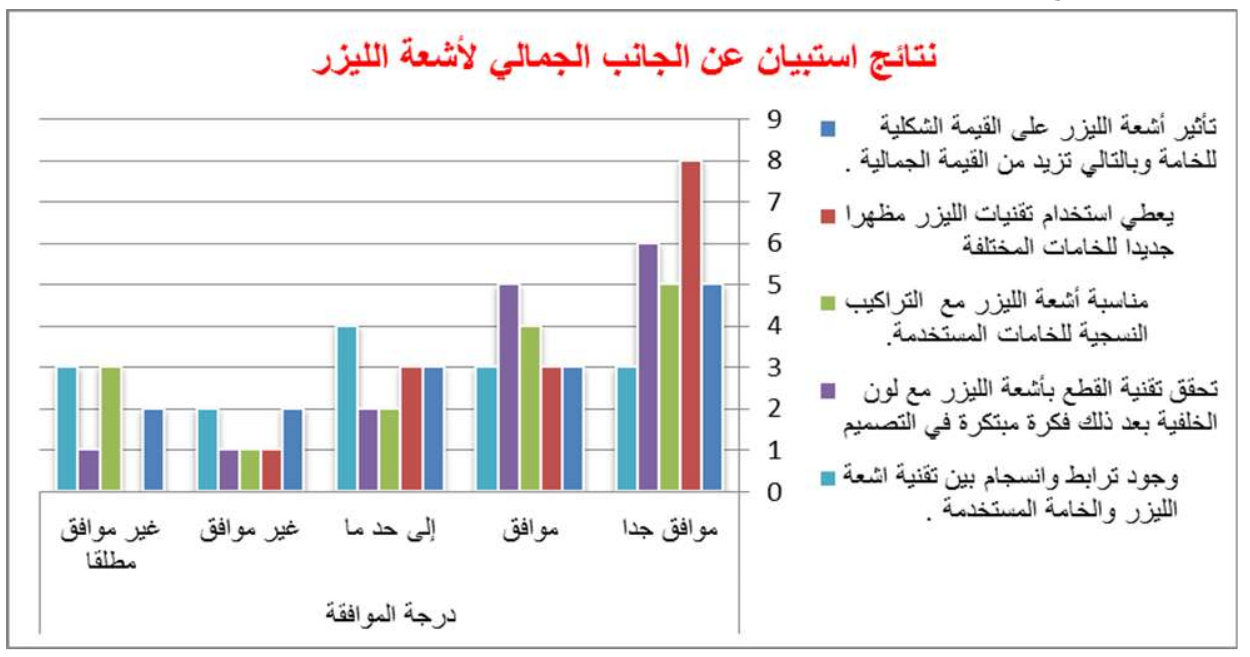

ثُالثا : من حيث الجاتب الاقتصادي :

الجدول النالي رقم (1) يوضح أراء المحكمين ونسبة تقييم كل محور :

\begin{tabular}{|c|c|c|c|c|c|c|c|c|c|}
\hline \multirow{2}{*}{ 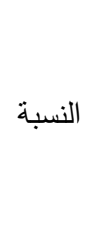 } & \multirow[b]{2}{*}{ 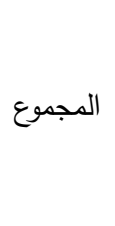 } & \multicolumn{5}{|c|}{ درجة الموافقة (عدد المحكمين ) } & \multirow[b]{2}{*}{ 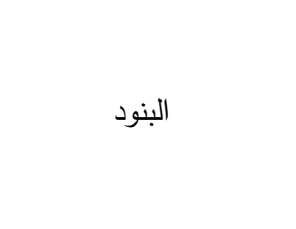 } & \multirow[b]{2}{*}{ r } & \multirow{6}{*}{$\overline{\bar{y}}$} \\
\hline & & موافق & غوافق & 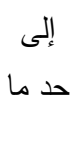 & 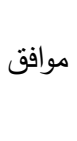 & جوافق & & & \\
\hline$\% \leq r$ & 10 & $r$ & $\varepsilon$ & $r$ & $r$ & r & قالفردى المنتج نتاسب الإنتاج & 1 & \\
\hline$\% \leqslant \vee$ & 10 & $r$ & r & $r$ & $\varepsilon$ & r & الحواكبة استخدام التكنولوجيا لإنتاج (الليزر ) & r & \\
\hline$\% \leq 7$ & 10 & $r$ & $r$ & $r$ & $r$ & $\varepsilon$ & تكلفة المنتج بعد استخدام & $r$ & \\
\hline$\%$ ov & 10 & $r$ & r & $r$ & $\varepsilon$ & 0 & مأكلفة استخدام الليزر & $\varepsilon$ & \\
\hline
\end{tabular}


من خلال الجدول السابق رقم (• (1) يتضح لنا آراء المحكمين من الناحية الجمالية ، وعدد

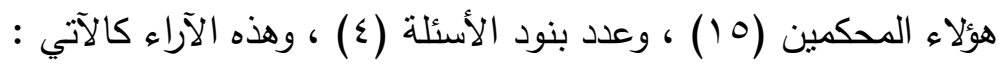

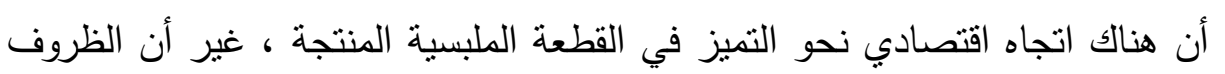

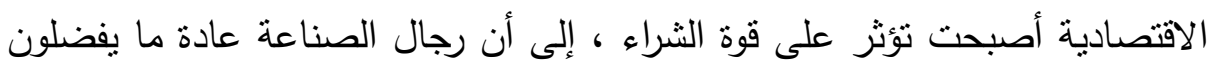

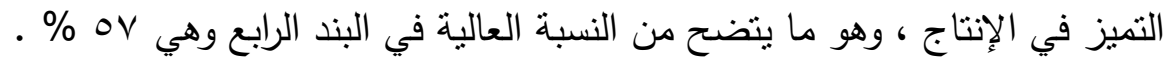
غير أن تكنولوجيا الليزر لا تتاسب الانتاج الكمي ، إلى أنها تعطي قطعة منتجة متفردة في القيمة الجمالية والفنية للتصميم ، وهو ما يتضح في البند الأول بنسبة تقييم . \% $\leqslant r$

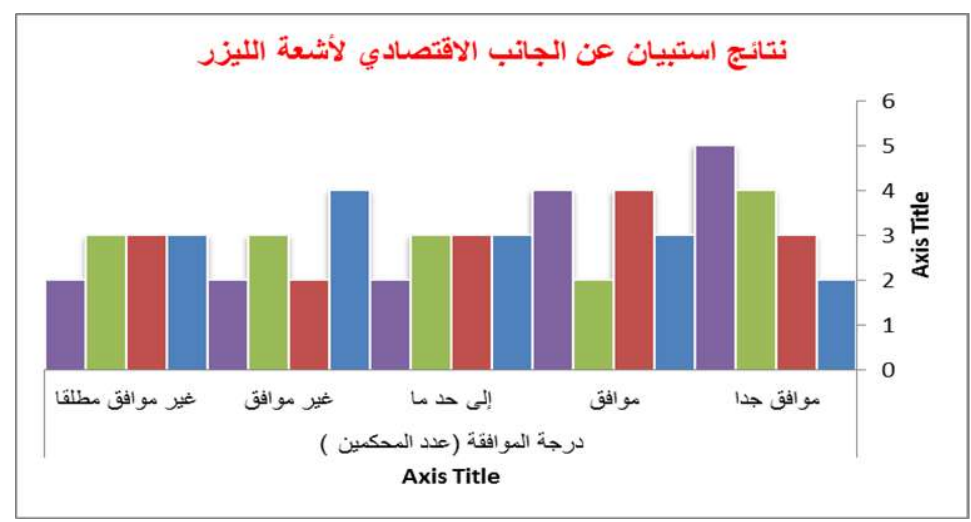

\section{التوصيات :}

بناءا على النتائج التي تم التوصل إليها والدراسة التطبيقية ، يوصى بالآتي :

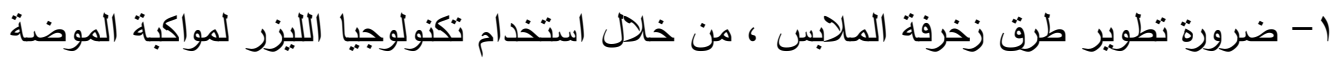
الحديثة ، والاهتمام باستحداث أساليب جديدة لتجميل الملابس ومكملاتها.

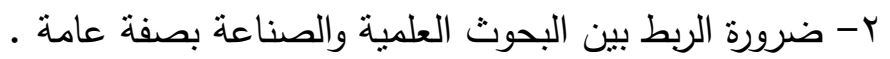
r- ضرورة تدريس برامج الجرافيك ( الفوتوشوب - الاليستريتور - الكوريل درو ) في مناهج كليات ومعاهد التصميم بصفة عامة ، وحيث أن استخدام تكنولوجيا اللبزر مرتبطة بدراسة هذه البرامج دراسة جيدة بصفة خاصة . كماهئ ع - ضرورة نوعية أصحاب المؤسسات الصناعية على إدخال ماكينات الليزر بصفة أساسية ضمن مجموعة الماكينات الأخرى الهامة والتي تستخدم في صناعة الملابس والنسيج • 


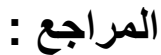

1-سوسن عبد اللطبف رزق : الحاسب في صناعة الملابس - عالم الكتب - ع ـ. بام .

2- Janette Matthews: "Textiles in three dimensions, An Investigation into processes employing laser processing to form design - led three dimensional textiles - PHD - 2011.

3- Roland Glaser: Biophysics, an Introduction - Second Edition - 2012.

ع- فاروق محمد العامري : تكنولوجيا الليزر واستخداماته العملية - الدار المصرية اللبنانية - الطبعة

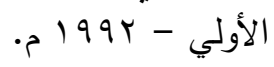

0- احمد الناغي ورشا فؤاد السيد : اثتعة الليزر واستخداماته في الطب - دار الفكر العربي- ب...

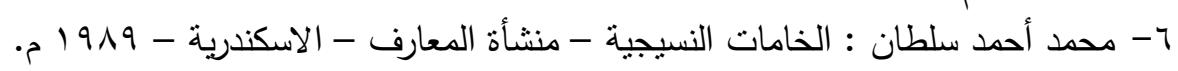

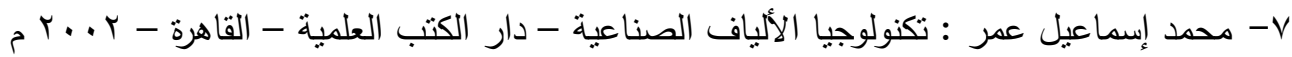

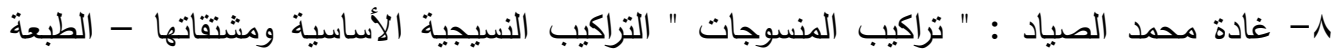

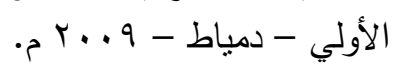

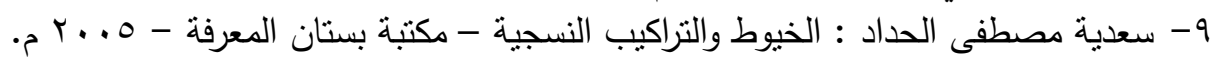
• ا-أنصاف نصر، كوثر الزغبي : دراسات في النسيج - دار الفكر العربي - القاهرة - الطبعة الفئة

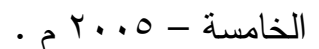

11-Premamoy Gosh: Fiber Science and Technology - Tata mc Groh ill publishing Co. Ltd - New Delhi - 2004.

r r-علي السيد زلط : الألياف والتراكيب النسجية - دار السلام للطباعة والنشر - المنصورة . r. . V

13-J. Gordon Cook: Handbook of Textile fibers - wood head publishing Ltd Cambridge - England - 2005 .

14-Kate Fletcher: Sustainable Fashion and Textiles - Earth Scan publishing U.S.A. -2008.

10-مها طلعت السيد : تحسين الآداء الوظيفي للأقشة المستخدمة في المجال الطبي بتجهيزها

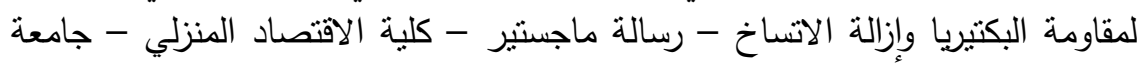

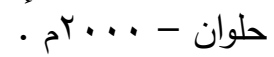

17 ا-سامي رزق بشاي - فاطمة محمد الثناوي : المشغولات الجلدية - وزارة التربية والتعليم - دار

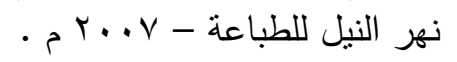

V ا-شريف عبد الجواد عبيد : فاعلية استخدام الكبيوتر في تعلم تقنبات الحياكة - رسالة دكتوراه -

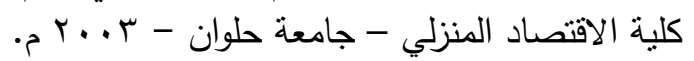

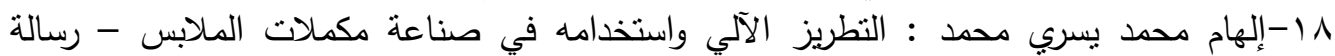

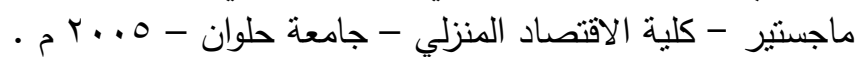

19-Parveen Bazaz: An exploration in to the impact of laser technology on to the fashion design process -2006 . 


\section{Laser Techniques Effect on Functions and Aesthetics of Garments}

برجاء اختبار التقدير المناسب من الاختبار ات الموجودة أمام بنود ومحاور الاستمارة. ولكم جزيل الثكر لحسن تعاونكم

الارسة

\begin{tabular}{|c|c|c|c|c|c|c|c|c|c|}
\hline \multirow[b]{2}{*}{ النسبة الن } & \multirow[b]{2}{*}{ 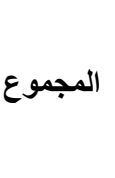 } & \multicolumn{5}{|c|}{ درجة الموافقة ( عدد المحكمين ) } & \multirow[b]{2}{*}{ 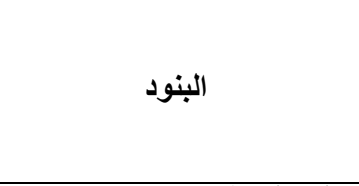 } & \multirow[b]{2}{*}{ p } & \\
\hline & & موافقي & موافق & 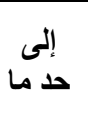 & موافق & موافق & & & \\
\hline & & & & & & & تأثير أنشعة الليزر على تلف & 1 & \\
\hline & & & & & & & 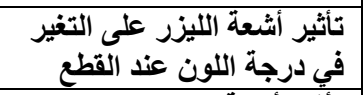 & r & \\
\hline & & & & & & & 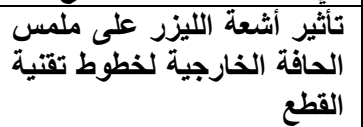 & $r$ & \\
\hline & & & & & & & وظيفتج بدرجة مقبولة الاستخام يؤدي & $\varepsilon$ & \\
\hline & & & & & & & 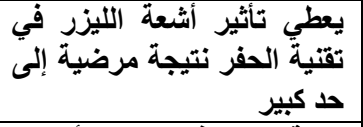 & • & \\
\hline & & & & & & & 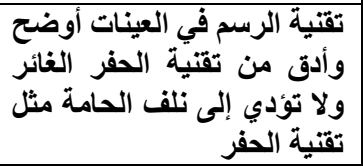 & 7 & \\
\hline \multirow{4}{*}{ النسبة } & \multirow[b]{2}{*}{ المجموع } & \multicolumn{5}{|c|}{ درجة الموافقة ( عدد المحكمين ) } & \multirow[b]{2}{*}{ البنود } & \multirow[b]{2}{*}{ r } & \\
\hline & & مولقي & موافير & 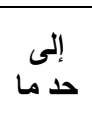 & 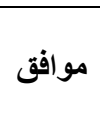 & موافق & & & \\
\hline & & & & & & & 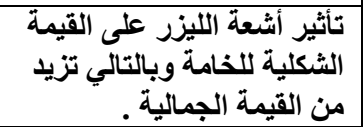 & 1 & \\
\hline & & & & & & & |مظهر| استخدام تقنتيات الليزر & r & \\
\hline
\end{tabular}




\begin{tabular}{|c|c|c|c|c|c|c|c|c|c|}
\hline & & & & & & & 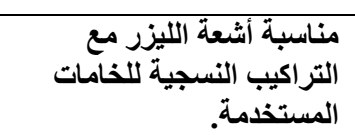 & $r$ & \\
\hline & & & & & & & 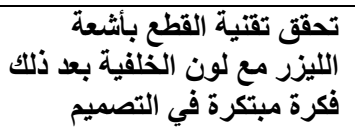 & $\varepsilon$ & \\
\hline & & & & & & & 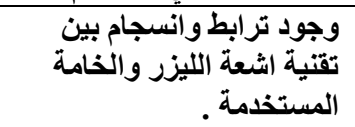 & • & \\
\hline \multirow{6}{*}{ النسبة الن } & \multirow[b]{2}{*}{ 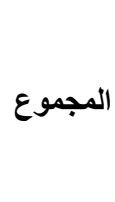 } & \multicolumn{5}{|c|}{ درجة الموافقة ( عدد المحكمين ) } & \multirow[b]{2}{*}{ 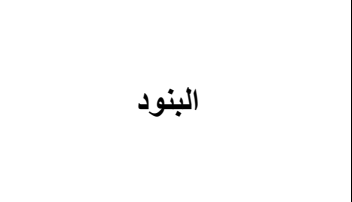 } & \multirow[b]{2}{*}{ p } & \\
\hline & & موافقير & مو غير & حذ ما & موافق & موافق & & & \\
\hline & & & & & & & قاقفيمة المنتج تنتاسب الإتتاج & 1 & \\
\hline & & & & & & & الحويثة لإتتاج (اللبزر ) التكنوجيا & $r$ & 商 \\
\hline & & & & & & & 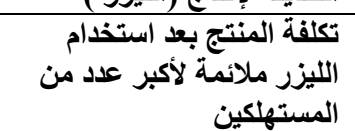 & $r$ & בy: \\
\hline & & & & & & & تلأصطحة استخدام المصانع والثركركات ملائمة & $\varepsilon$ & \\
\hline
\end{tabular}


ملحق رقم (r)

قائمة بأسماء السادة المحكمين

\begin{tabular}{|c|c|c|}
\hline الوظيفة & الاسم & م \\
\hline أستاذ تكنولوجيا الانتاج بكلية الفنون التطبيقية - & أ.د/ أحمد حسني خطاب & 1 \\
\hline أستاذ مساعد بكلية التربية النو عية - جامعة بنها & أ.م.د/ ايناس محمد الدرديري & r \\
\hline أستاذ مساعد بكلية التربية النو عية - جامعة بنها & أ.م.د/ مني عبد الهادي شاهين & $r$ \\
\hline مدرس بكلية الفنون التطبيقية - جامعة بنها & م.م/ أحمد فهيم البربري & $\varepsilon$ \\
\hline مدرس مساعد بكلية الفنون التطبيقية - جامعة & م.م / نهى مجدي ابر اهيم علي & ० \\
\hline ملورس مساعد بكلية الفنون التطبيقية - جامعة & م.م / كريمان علي بك & 7 \\
\hline مدرس بكلية الفنون التطبيقية - جامعة بنها & م.م/ منى سيد نصر & $\mathrm{V}$ \\
\hline مركز الليزر بجامعة القاهرة & أ.م.د/ محمد زين & $\Lambda$ \\
\hline المركز القومي للبحوث & أ.م.د/ حسن إبر اهيم & 9 \\
\hline صاحب مصنع كلير لملابس الأطفال & أ/إبر اهيم على محمد & 1. \\
\hline مدير تخطيط شركة لومكس لملابس الأطفال & م/محمد عاصم عفيفي & 11 \\
\hline الحريمي الإدارة الفنية لثركة فيلاتو للملابس & أ/محمد خضرة & ir \\
\hline مدير إنتاج بمصنع ملابس & أ/ أحمد هادي & 14 \\
\hline مستهرلك & أ/أسماء أحمد حسن & $1 \leq$ \\
\hline مسترهلك & أ/ صبري على جودة & 10 \\
\hline
\end{tabular}

